\title{
Cytologische Veränderungen während der Metamorphose des Cubopolypen Tripedalia cystophora (Cubozoa, Carybdeidae) in die Meduse
}

\author{
G. Laska-Mehnert \\ Zoologisches Institut der Universität Bonn; Poppelsdorfer Schloß, D-5300 Bonn, \\ Bundesrepublik Deutschland
}

\begin{abstract}
Cytological changes during the metamorphosis from the cubopolyp Tripedalia cystophora (Cubozoa, Carybdeidae) to a medusa. The life cycle of Tripedalia cystophora includes a sessile saclike polyp - the asexual reproducing form - and a pelagic tetraradial medusa - the sexually reproducing generation. Medusan development can be induced by temperature increase. It reveals neither budding nor strobilation, but a real metamorphosis of a polyp to only one medusa. According to morphological and anatomical criteria the metamorphosis can be subdivided into four different stages: (1) four longitudinal furrows segment the polyp, the tentacles of which are apportionated on the four quadrants of the body. (2) The subumbrellar cavity develops by invagination of the peristom; the relicts of the fused tentacles change to four rhopalia buds. (3) Medusan architecture including four new interradial tentacles, four rhopalia and the subumbrellar swimming musculature is completed. (4) A young tetraradial medusa starts swimming. Ultrastructural analysis of those metamorphic stages show the different processes of morphogenesis: (a) Gastrodermal cells - absorptive and spumous cells - undergo transdifferentiation and proliferation to medusan cells of the same structure and function. (b) Epidermal cells, excluding the epithel muscle cells, dissociate and are autolytically withdrawn. Dedifferentiated epithel muscle cells - interstitial cells - regain the ability to develop a complete new set of somatic cells, not originally present in the polyp. They include amongst others cross-striated muscle cells, medusan typic nematocyts and particularly sensory and nervous cells. Those cells establish a nervous system with lens-eyes, simple ocelli, statocysts, diffuse nerve net and an additional nerve ring.
\end{abstract}

\section{EINLEITUNG}

Seit der vollständige Lebenszyklus der tropischen Cubomeduse Tripedalia cystophora Conant, 1897 (Werner et al., 1971; Werner, 1973, 1975) bekannt ist, halten im Gegensatz zu Hennig (1979) immer mehr Autoren die Errichtung einer eigenen Klasse Cubozoa für erforderlich (Werner, 1976; Chapman, 1978; Pearse \& Pearse, 1978; Yamaguchi \& Hartwick, 1980). Neben zahlreichen Unterscheidungsmerkmalen, die den Bau der Polypen und Medusen betreffen, ist es vor allem die Art der Medusenbildung, die sie von allen anderen Cnidariern unterscheidet (Werner, 1983). Während schon Kühn (1910) die Ontogenese der Hydromedusen durch laterale Knospung und die der Scyphomedusen durch monodiske oder polydiske Strobilation beschrieben hat, wurde die ungewöhnliche Medusenbildung der Würfelquallen, in deren Verlauf sich der Polyp durch eine vollständige Metamorphose in nur eine Meduse umwandelt, erst durch Werner et 
al. (1971) an T. cystophora nachgewiesen und später an Carybdea alata (Arneson \& Cutress, 1976) und Chironex fleckeri (Yamaguchi \& Hartwick, 1980) bestätigt.

Die äußerlich erkennbaren Vorgänge der Metamorphose und die inneren anatomischen Veränderungen wurden bereits von Werner $(1975,1983)$ beschrieben. Die vorliegende Arbeit untersucht die tiefgreifenden cytologischen Veränderungen während der Metamorphose, wobei ein besonderer Schwerpunkt auf der Morphogenese der bisher nur in ihrem Bau untersuchten Linsenaugen (Conant, 1898; Yamasu \& Yoshida, 1976; Laska \& Hündgen, 1982) liegt. Die Ergebnisse stellen die notwendige Ergänzung zur cytologischen Untersuchung des Cubopolypen (Chapman, 1978) dar und gestatten eine weiterführende Erörterung der Verwandtschaftsbeziehungen der Cubozoa.

\section{MATERIAL UND METHODEN}

\section{Tiermaterial}

Laborzuchten des ursprünglich aus Puerto Rico stammenden Materials wurden uns von Dr. Werner (Biologische Anstalt Helgoland, Hamburg) zur Verfügung gestellt. Sie wurden auf Uhrgläschen sitzend in belüfteten Seewasser-Aquarien bei $23^{\circ} \mathrm{C}$ zur vegetativen Fortpflanzung gebracht. Als Nahrung dienten 3 Tage alte Nauplien von Artemia salina. Durch die Erhöhung der Wassertemperatur auf $28{ }^{\circ} \mathrm{C}$ konnte die Metamorphose induziert werden.

\section{Präparationsgang}

(1) Anästhesie: Um eine Kontraktion der Umwandlungsstadien zu verhindern, erhielten diese eine Anästhesie mit einer $7 \%$ igen $\mathrm{MgCl}_{2}$-Lösung.

(2) Fixierung: $1 \%$ Glutaraldehyd und $5 \%$ Rohrzucker in $0,1 \mathrm{M}$ Collidin-, $0,1 \mathrm{M}$ Cacodylat- oder $0,1 \mathrm{M}$ Natriumphosphatpufferlösung.

$1 \%$ Osmiumtetroxid und $5 \%$ Rohrzucker in 0,1 M Milloning-Puffer; jeweils pH 7,3, $4{ }^{\circ} \mathrm{C}, 2$ Std.

(3) Wässerung in den angegebenen Pufferlösungen, $20^{\circ} \mathrm{C}, 6 \times 15 \mathrm{~min}$.

(4) Kontrastierung nach Glutaraldehydfixierung: $1 \% \mathrm{OsO}_{4}$ in $0,1 \mathrm{M}$ Collidinpuffer, $\mathrm{pH}$ $7,3,4{ }^{\circ} \mathrm{C}, 4$ Std.

(5) Wässerung in den angegebenen Pufferlösungen, $20^{\circ} \mathrm{C}, 3 \times 15 \mathrm{~min}$.

(6) Entwässerung in Äthylalkohol von 15\%igem bis zum absoluten Alkohol in sieben Stufen bei $20^{\circ} \mathrm{C}$, insgesamt 8 Std.

(7) Nachkontrastierung in 70\%igem Athylalkohol mit 1\% Phosphorwolframsäure und $1 \%$ Uranylacetat, $4{ }^{\circ} \mathrm{C}, 4$ Std.

(8) Einbettung: Styrol-Methacrylat.

(9) Mikrotomie: Reichert Mikrotom OM U3.

(10) Mikroskopie: Leitz Dialux; Elektronenmikroskopie Zeiss EM 9 S2 und Siemens Elmiskop I.

Die Fixierungsmethoden werden durch die folgenden Zahlen in allen Abbildungsunterschriften mit angegeben: Fix. $1=1 \%$ Glutaraldehyd in $0,1 \mathrm{M}$ Collidinpuffer; Fix. $2=1 \%$ Glutaraldehyd in $0,1 \mathrm{M}$ Cacodylatpuffer; Fix. $3=1 \%$ Glutaraldehyd in $0,1 \mathrm{M}$ Natriumphosphatpuffer; Fix. $4=1 \%$ Osmiumtetroxid in $0,1 \mathrm{M}$ Milloning-Puffer. 


\section{ANATOMIE DER FORMBILDUNGSPROZESSE}

Im Verlaufe der für die Cubozoa charakteristischen Umdifferenzierungen des Polypen zur Meduse wird der Polyp von apikal nach basal innerhalb eines Zeitraumes von 6-8 Tagen in seiner Anatomie verändert. Die Entwicklung kann nach morphologischen Kriterien in drei Stadien gegliedert werden, denen im Folgenden die Beschreibung des polypen voran-, die der Meduse nachgestellt werden soll.

\section{Der adulte Polyp}

Tripedalia cystophora lebt bei Temperaturen um $23^{\circ} \mathrm{C}$ als ein sich asexuell fortpflanzender, solitärer Polyp (Abb. 1a). Dieser mißt 0,5-1 mm in seiner Länge und besitzt einen birnenförmigen Körper, der mit Hilfe einer flachen, von der basalen Epidermis sezernierten Peridermhülle im Fußbereich am Substrat festsitzt. Rund um den Mundkegel (MK in Abb. 1a und b) steht ein einzelner Kranz von 7-9 capitaten Tentakeln ( $\mathrm{T}$ in $A b b .1 a$ und $b)$. Der sackförmige, ungegliederte Körper besitzt eine zweischichtige Wand (ED und GD in Abb. 1b) mit dünner Mesogloealamelle (MG in Abb. 1b) Die Tentakel sind von einer Reihe hochvakuolisierter Gastrodermiszellen (GD in Abb. 1b) solide ausgefüllt. Das Monocnidom des Polypen besteht aus mikrobasischen Eurytelen. Charakteristisch für Cubopolypen ist ein entodermal-ektodermales Nervenringpaar, das in Höhe des Tentakel-Oralkonus-Überganges liegt. Die Polypenknospung erfolgt im basalen Teil des Polypen, direkt oberhalb des Peridermbechers.

Eine Temperaturerhöhung von $23^{\circ}$ auf $27^{\circ} \mathrm{C}$ induziert bei adulten Polypen die Metamorphose zur Meduse über die folgenden Stadien:

\section{Stadium 1}

Im Metamorphosestadium 1 wird der ursprünglich runde Polypenkörper durch vier symmetrische Längsfurchen ( - in Abb. 2a) tetraradial, wobei die 7-9 Tentakel ( $T$ in Abb. 2a) auf die vier Quadranten (I-IV in Abb. 2a) verteilt werden und jeweils basoapikal fusionieren. Die Körperepithelien $\left(E D_{1}\right.$ und $G_{1}$ in $\left.A b b .2 b\right)$ bleiben noch unverändert einschichtig, während die Tentakelbasen nach der Fusion eine vielschichtige Epidermis und Gastrodermis $\left(\mathrm{ED}_{2}\right.$ und $\mathrm{GD}_{2}$ in $\mathrm{Abb}$. 2b) zeigen. Zwischen den Tentakelbasen wachsen schließlich vier neue Medusententakel aus, die zusätzlich zum alten Nesselzelltyp der mikrobasischen Eurytelen auch holotriche und basitriche Haplonemen differenzieren.

\section{Stadium 2}

Nun greifen die Veränderungen von den Tentakeln auf den Körper des Polypen über. Eine oberflächliche Horizontalfurche ( - in Abb. $3 a$ und b) gliedert den Polypenkörper in den Tentakel-tragenden bräunlich pigmentierten Apikalteil mit sich abflachenden Medusenepithelien (AT in Abb. 3a und b) und den weißlichen Basalteil (BT in $\mathrm{Abb}$. 3a und b) mit den noch unveränderten, hochprismatischen, polypentypischen Epithelien. Radial entwickeln sich die vier ehemaligen Tentakelbasen des Polypen zu den Rhopalien ( $\mathrm{Rh}$ in $\mathrm{Abb}$. 3a und b). Gleichzeitig senkt sich das Peristom ringförmig zur Subumbrellarhöhle ein. Die Horizontalfurche markiert jeweils die tiefste Stelle der sich 

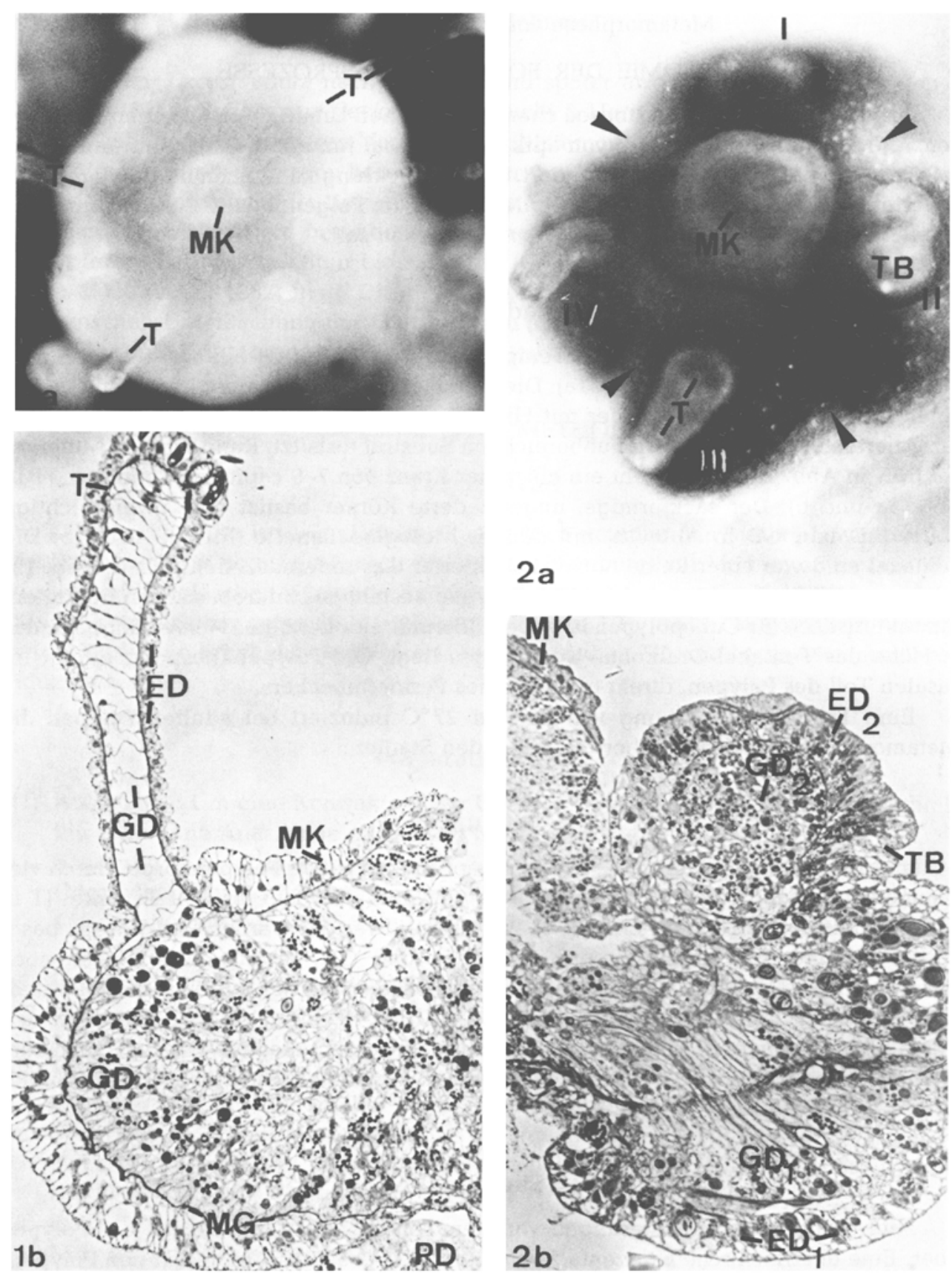

Abb. 1 und 2. Polypen von Tripedalia cystophora. 1a Lebendaufnahme eines adulten Polypen, $200 \mathrm{x}$. $1 b$ Semidünner Längsschnitt eines Polypen mit ungegliedertem Körper, einschichtiger Epidermis (ED) und Gastrodermis (GD), 350x. 2a Polyp in Metamorphose; Stadium 1, 300x. I-IV Körperquadranten, die durch Längsfurchen (-) entstehen. $2 b$ Radialer Längsschnitt mit vielschichtigem Tentakelrelikt mit Epidermis $2\left(\mathrm{ED}_{2}\right)$ und Gastrodermis $2\left(\mathrm{GD}_{2}\right)$; $350 \mathrm{x}$. MG Mesogloea, MK Mundkegel, PD Periderm, T Tentakel, TB Tentakelbasis 

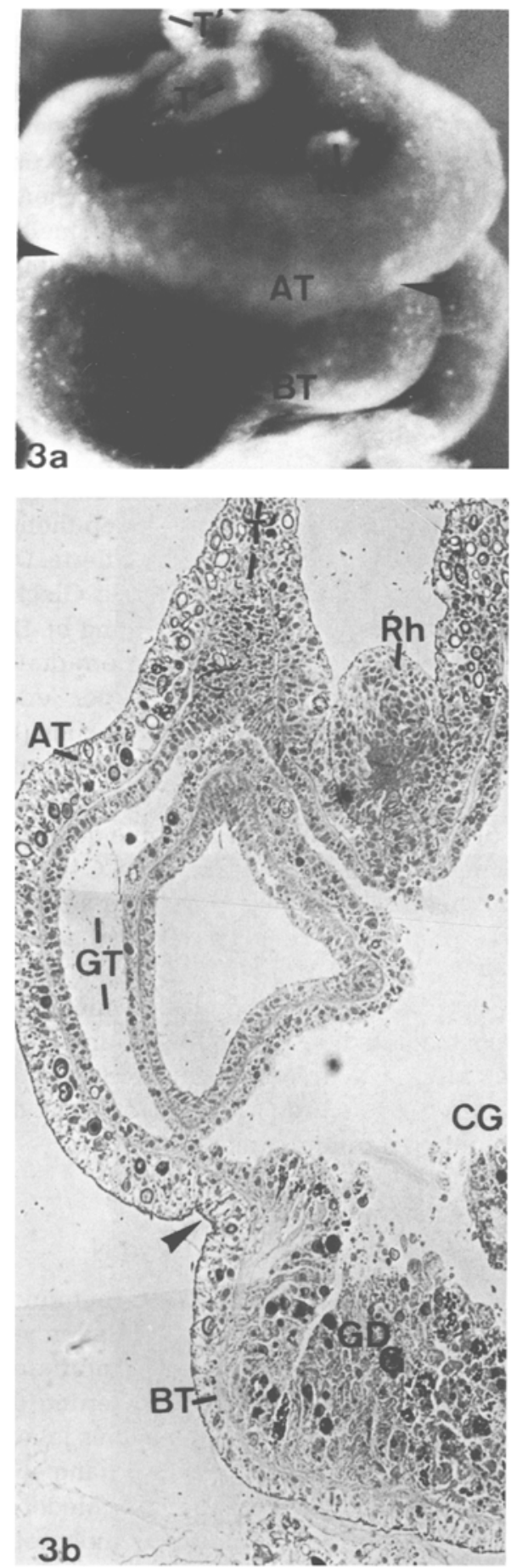
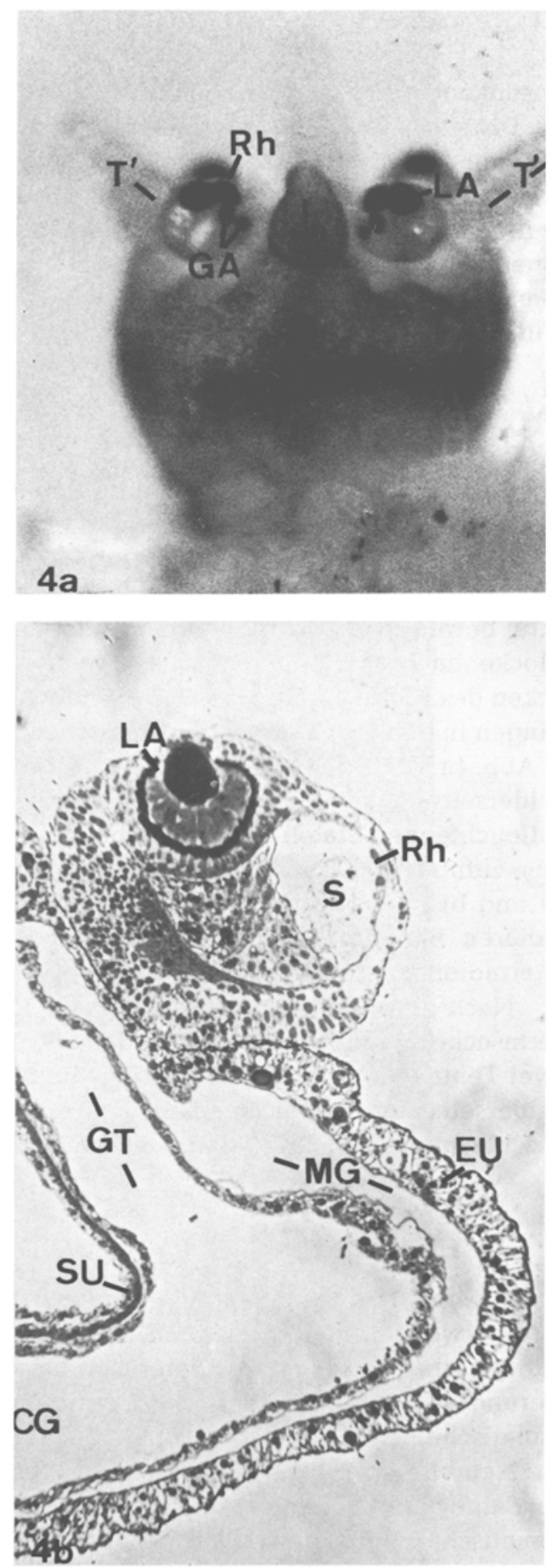

Abb. 3 und 4. Polypen von Tripedalia cystophora in Metamorphose. 3a Stadium 2, fixiert; 200x. $3 b$ Längsschnitt durch einen Adradius mit Tentakel ( $\left.\mathrm{T}^{\prime}\right)$, Rhopalien-tragendem Apikalteil (AT) und unverändertem Basalteil (BT); 300x. 4a Stadium 3; Lebendaufnahme, 250x. $4 b$ Längsschnitt durch Adradius mit einheitlicher Glockenwand und Rhopalium (Rh), 300x. CG Centrogaster, GA Grubenauge, GD Gastrodermis, EU Exumbrella, GT Gastraltasche, LA Linsenauge, MG Mesogloea, RH Rhopalium, S Statolith, SU Subumbrella, T' Medusententakel, - Horizontalfurche 
einsenkenden Subumbrella und die Basis des zum Manubrium verlängerten Mundrohres. Die sackförmig ungegliederte Gastralhöhle des Polypen (GH in Abb. 6a) wird dabei in einen stielförmigen Zentralteil - Manubrium und Centrogaster (CG in Abb. 3b und 7a) - sowie einen damit verbundenen Außenring - die späteren 4 Gastraltaschen gegliedert. In den Interradien werden die Gastraltaschen durch Entodermlamellen voneinander getrennt. Echte Septen fehlen den Cubomedusen. Das Manubrium nimmt ebenso wie die Glocke quadratische Form an. Am Schirmrand wächst das Velum (Ve in Abb. 7a) als epidermale Falte aus.

\section{Stadium 3 und die Jungmeduse}

Im Stadium 3 fehlt dem metamorphosierenden Polypen (Abb. 4a) eine Gliederung in Apikal- und Basalteil. Die Körperepithelien sind medusentypisch zu Plattenepithelien abgeflacht. Die Mesogloea (MG in Abb. 4b) wird zur formgebenden Schirmgallerte. Das noch sessile Stadium besitzt bereits alle Medusenmerkmale wie kontraktile Glocke, aktiv bewegliche Tentakel und ausdifferenzierte Rhopalien (Rh in Abb. 4a und b). Die Glocke hat durch allometrisches Wachstum Würfelform erhalten; die interradialen Ecken des Würfels tragen die Medusententakel ( $\mathrm{T}^{\prime}$ in Abb. 4a). Auf der Mitte der Seiten hängen in den sogenannten Sinnesnischen an beweglichen Stielchen die Rhopalien ( $R h$ in $A b b .4 a$ und $b, 5 a$ und $b$ ), die zwei unterschiedlich große Linsenaugen (LA in Abb, 4a), beiderseits davon je zwei Grubenaugen (GA in Abb. 4a) und einen kristallähnlich aufleuchtenden Statolithen ( $\mathrm{S}$ in $\mathrm{Abb}, 4 \mathrm{~b}$ und 5) tragen. Das Velum läßt eine quadratische Offnung frei; und auf der Glockenoberfläche ordnen sich Nesselzellen (CC in Abb. $5 a$ und b) zu einem für Tripedalia cystophora typischen Muster an, welches aus acht radiären Bändern besteht, die von der Spitze der Glocke aus in den Radien und Interradien zum Glockenrand verlaufen.

Nach einer kurzen Wachstumsphase löst sich die Jungmeduse vom kleinen Peridermsockel $\mathrm{ab}$ und verändert sich danach nur noch durch die zusätzliche Bildung von je zwei Tentakeln pro Interradius sowie die Entwicklung von entodermalen Gonaden, die beiderseits der Entodermlamellen sitzen. Innerhalb von drei Monaten erreicht die geschlechtsreife Meduse eine Größe von 15-20 mm Schirmdurchmesser.

\section{HISTOLOGIE UND CYTOLOGIE DER METAMORPHOSESTADIEN}

Während der Metamorphose laufen morphogenetische Prozesse ab, die mit einem Strukturwandel, häufig auch mit einem Funktionswandel der somatischen Zellen verbunden sind. Dieses Transdifferenzierungsgeschehen erfolgt durch direkte Umdifferenzierung von einem Zelltyp zu einem anderen, oder durch die Dedifferenzierung der somatischen Zellen zu indifferenten, I-Zellen ähnlichen Stadien, von denen ausgehend die Neudifferenzierung eingeleitet wird. Letztere kann schließlich ihren Ausgang auch von einem heterogenen Aggregat von Zellen nehmen, das sich aus verschiedenen somatischen Zellen sowie aus I-Zellen bzw. I-Zell-ähnlichen Stadien zusammensetzt. Elektronenmikroskopisch sind von diesen Vorgängen lediglich die Änderung der Form, der Zellstruktur und der Teilungsaktivität sowie die dann einsetzende Musterbildung erfaßbar. 

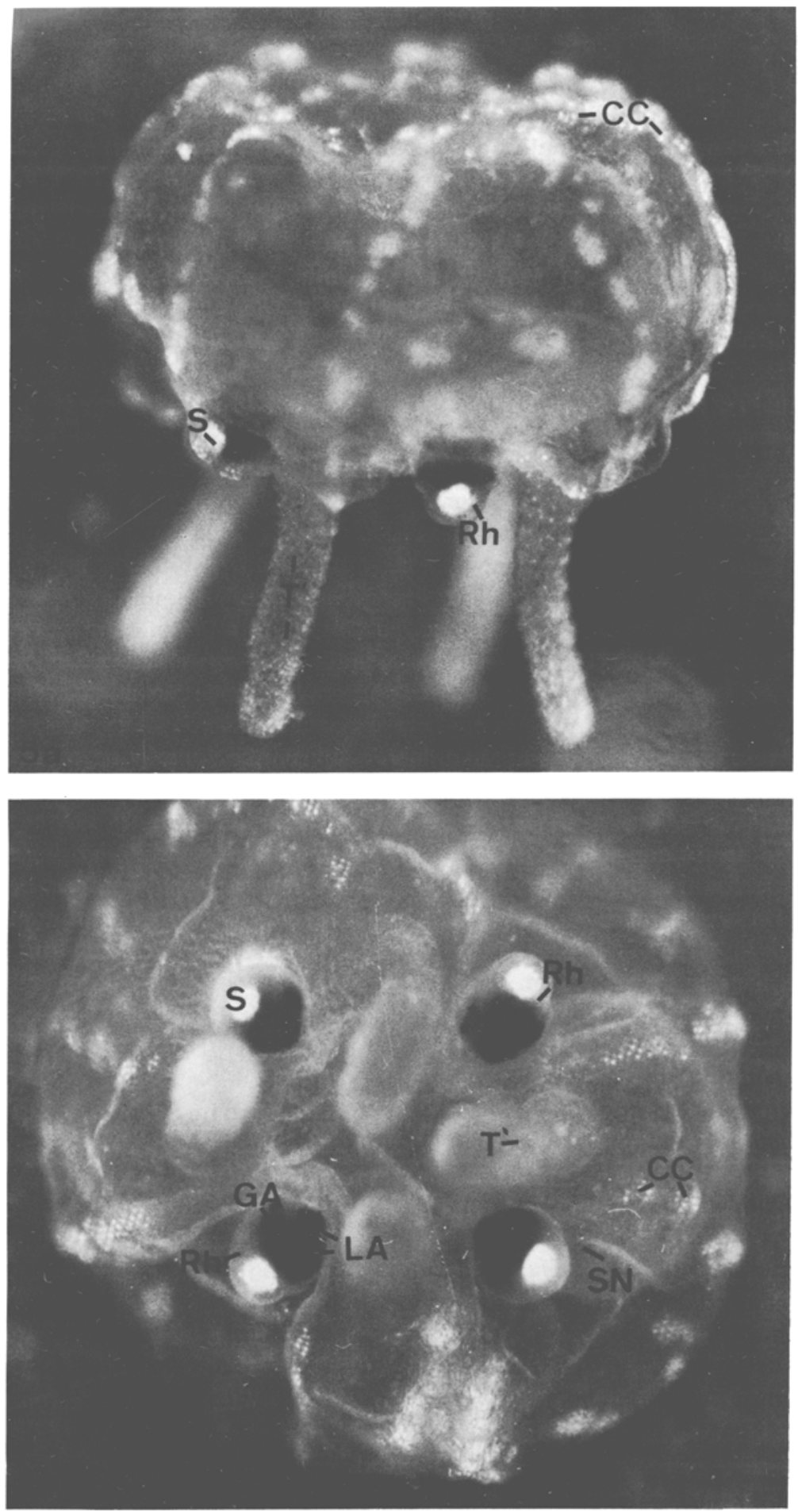

Abb. 5. Jungmeduse von Tripedalia cystophora. a Seitenansicht auf die radialen Sinnesnischen mit den Rhopalien (Rh) und den interradialen Tentakeln (T), 200x. b Aufsicht mit Glockenrand, 200x. CC Cnidocyten, GA Grubenauge, LA Linsenauge, S Statolith, SN Sinnesnische 


\section{Morphogenese der Exumbrella und des Gastrovaskularsystems}

Die Körperwand des Polypen besteht aus einer äußeren Lage palisadenförmiger Epidermiszellen (ED in Abb. 6a) und einer inneren Lage hochprismatischer Gastrodermiszellen (GD in Abb. 6a), die durch eine dünne Mesogloea (MG in Abb. 6a) voneinander getrennt sind. Bis auf einige Cnidoblasten und wenige macrogranuläre Zellen sowie die Anteile des Nervennetzes wird die Epidermis von Epithelmuskelzellen (EMZ in Abb. 6b) gebildet. Diese haben die Gestalt eines Zylinders, der sich in den Apikalteil mit großer zentraler Vakuole (Va in Abb. 6b) und einem Somateil mit dem Kern ( $N$ in Abb. 6b) gliedert. Der mesogloeanahe Somateil entwickelt kurze Zellfortsätze, welche die kontraktilen Elemente der glatten Längsmuskulatur des Polypen enthalten. Der epidermalen Längsmuskulatur liegt eine schwache Ringmuskulatur der Gastrodermis gegenüber.

Charakteristisch für die Frühphase der Metamorphose ist die Verformung der Epidermiszellen sowie der Abbau ihrer glatten Myofibrillen: Nach einer kurzen hochprismatischen Phase (Abb. 6b) flachen sich die Epidermiszellen ab und bilden ein Plattenepithel (Abb. 6c). Die in der Polypenepidermis vollständig fehlenden I-Zellen sind vom Stadium 2 an vereinzelt zu finden. Häufiger als beim Polypen findet man macrogranuläre Zellen, epidermale Drüsenzellen, deren vesikulärer Inhalt jenem der Zymogenzellen ähnelt.

Im Gegensatz zur Hydranthenepidermis, die insgesamt zur Exumbrella umdifferenziert wird, verändert sich die Gastrodermis des einheitlichen Polypenhohlraumes (GH in Abb. 6a) in Abhängigkeit von ihrer Lage. Sowohl beim Polypen als auch im Stadium 1 besteht die hochprismatische Gastrodermis (GD in $\mathrm{Abb}$. $6 \mathrm{a}$ und $7 \mathrm{~b}$ ) aus schmalen, vesikelreichen Nährzellen ( $N a ̈ Z$ in $\mathrm{Abb} .7 \mathrm{~b}$ und 3 in $7 \mathrm{a}$ ) mit typischen Nahrungsvakuolen, sowie Drüsenzellen, die vor allem in der basalen Hälfte dichte Ansammlungen polymorpher, osmiophiler Grana aufweisen. Zymogenzellen sind selten. Während der Metamorphose verarmen die Schleimzellen (gSZ in Abb. 7b) zunächst in ihrem basalen Bereich an den osmiophilen Grana. Differenzieren sie sich zu Nährzellen (NäZ in Abb. 7c) der Gastraltaschen, so flachen sie stark ab. Bereits in den noch weitlumigen Taschen des Stadiums 2 sind ausschließlich Nährzellen in der Gastrodermis zu finden. Die nun kubischen Zellen enthalten im Zentrum einen Zellkern ( $N$ in $A b b .7 c)$ mit großem Nukleolus, umgeben von organellenreichem Zytoplasma. Neben den zahlreichen Dictyosomen und Nahrungsvakuolen ( $\mathrm{NaV}$ in $\mathrm{Abb}$. $7 \mathrm{c}$ ) werden im Stadium 2 kleine zentrale Vakuolen gebildet. Im Stadium 3 flachen sich die Zellen der stark verengten Gastraltaschen zu ihrer typischen Medusen-Epithelform ab. Zymogen- und Schleimzellen fehlen in den radialen Gastraltaschen der Jungmeduse. Die Gastrodermis des Peristoms bleibt

\footnotetext{
Abb, 6 und 7. Tripedalia cystophora. Die Transdifferenzierung von Polypen-zu Medusengewebe. $6 a$ und 7a. Schematische Darstellungen mit Ausschnitt aus der Körperwand von Polyp (6a) und Meduse (7a). $6 b$ und $c$ Längsschnitte durch die Magenregion; $b$ im Stadium 1 mit hochprismatischen Epithelzellen, 4500x. $c$ im Stadium 3 mit Plattenepithelzellen (EZ), 4500x; jeweils Fix. 1. $7 b$ Gastrodermis im Stadium 1 mit hochprismatischen granulären Schleimzellen (gSZ) und Nährzellen (NäZ), 4500x. $7 \mathrm{C}$ im Stadium 3: abgeflachte Nährzellen mit großen Nahrungsvakuolen (NaV), 4500x, je Fix. 1. B Polypenbasis, CG Centrogaster, EL Entodermlamelle, EMZ Epithelmuskelzelle, EZ Epithelzelle, GD Gastrodermis, GH Gastralhöhle, GT Gastraltasche, MG Mesogloea, MK Mundkegel, N Nukleus, R/I Radius und Interradius, Rh Rhopalium, SV Sekretvesikel, T/T'Polypententakel/Medusententakel, Va Vakuole, Ve Velum, $1=$ Schleimzelle, $2=$ Zymogenzelle, $3=$ Nährzelle
} 

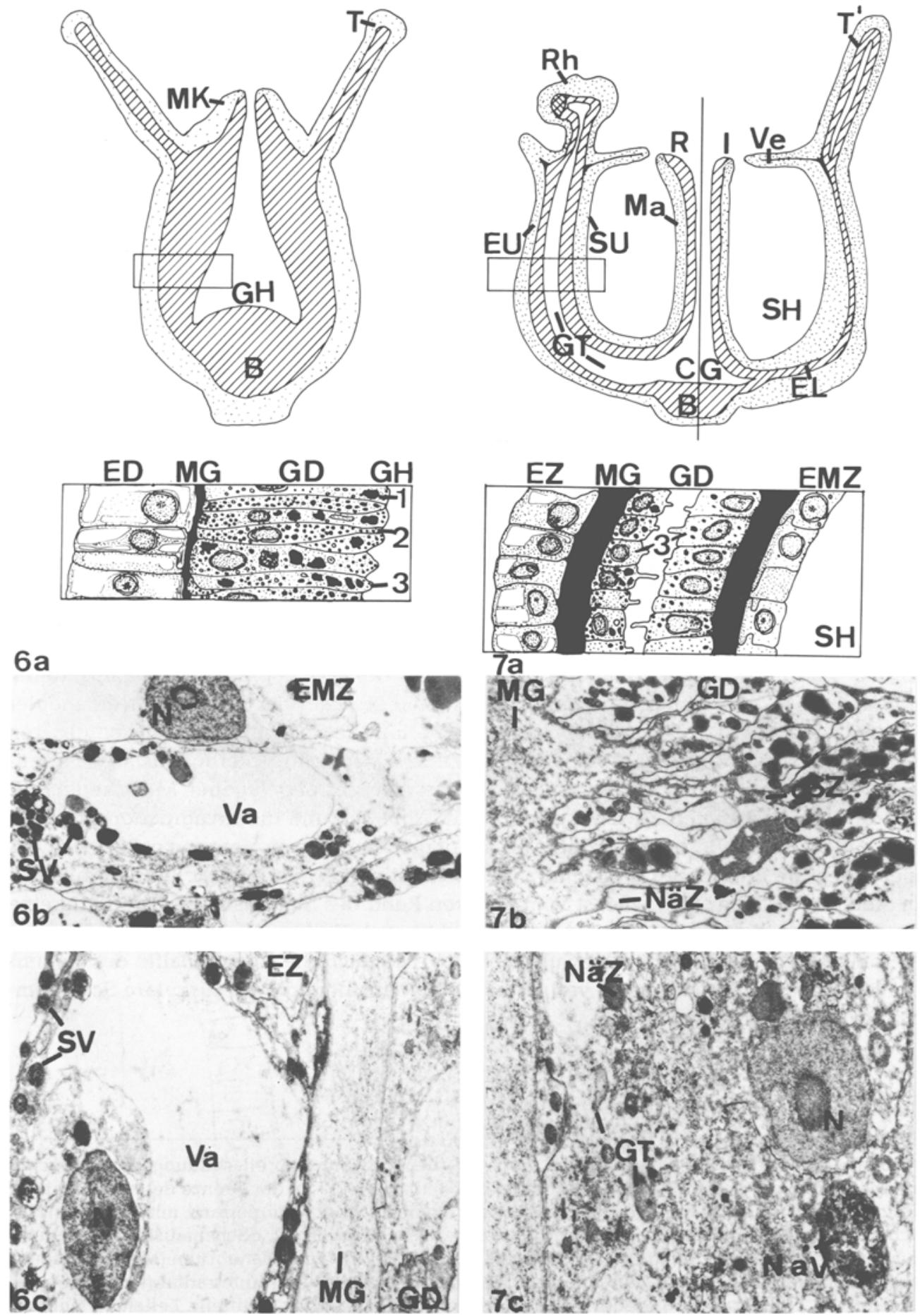
während der Metamorphose ebenso wie die des Somateiles einschichtig und folgt der Invagination der Subumbrella passiv. Die Auskleidung des sich zum Manubrium (Ma in $\mathrm{Abb} .7 \mathrm{a}$ ) verlängernden Mundkegels (MK in Abb. 6a) mit granulären Schleimzellen und Nährzellen bleibt unverändert. In den Zellen werden jedoch die großen zentralen Vakuolen abgebaut und glatte Muskulatur synthetisiert. Die hochprismatischen Gastrodermiszellen der Polypenbasis ( $\mathrm{B}$ in $\mathrm{Abb} .6 \mathrm{a}$ und $7 \mathrm{a}$ ) differenzieren zum überwiegenden Teil zu den Zymogenzellen des Zentralmagens (CG in Abb. 7a). Weniger häufig sind hier Nährzellen und Schleimzellen zu finden. Die Mesogloea (MG in Abb. 6a, 7a und b) nimmt im Verlaufe der Metamorphose deutlich an Dicke zu.

Die Zellen der Hydranthenepidermis und des gesamten gastrodermalen Hohlraumes des Polypen bilden somit durch Umdifferenzierung und Vermehrung der Zellen durch Mitosen die Exumbrella und das nun tetramer gegliederte Gastrovaskularsystem der Meduse.

\section{Morphogenese von Subumbrella, Velum und Tentakeln}

Dem Peristom kommt im Verlauf der Metamorphose besondere Bedeutung zu. Bereits nach der Verschmelzung der Polypententakel im Stadium 1 ist die ehemals einschichtige Epidermis im Grenzbereich zu den Tentakelrelikten vielschichtig (PS in Abb. 8a). Dies ist auch in den Interradien der Fall. Hier liegen I-Zellen (IZ in Abb. 8a und b) in großer Zahl zwischen den disorganisierten Epithelzellen des Polypen. Die rundlich bis kubisch geformten Zellen enthalten neben dem großen, runden, nukleolushaltigen Kern eine dichte Population freier Ribosomen und wenig endoplasmatisches Retikulum. Mit Einsetzen der Differenzierung vergrößert sich die Zahl der Mitochondrien und der Golgi-Zisternen. In das benachbarte Mundkegelepithel (MK in Abb. 8a) immigrieren keine dieser I-Zellen, sodaß hier die Epidermis einschichtig bleibt. Das sich einsenkende Peristom (PS in Abb. 8a und b) verlängert den zentral gelegenen Mundkegel (MK in $\mathrm{Abb} .8 \mathrm{~b}$ ) zum späteren Manubrium (Ma in $\mathrm{Abb} .8 \mathrm{c}$ ); und die Invagination erweitert sich zur Subumbrellarhöhle ( $\mathrm{SH}$ in $\mathrm{Abb} .8 \mathrm{~b}$ und c). Bei diesem Vorgang ordnet sich das vielschichtige Epithel des Peristoms zur einschichtigen Epidermis der Subumbrella (SU in Abb. 8c). Gleichzeitig wächst vom äußeren Rand des Schirms irisblendenartig eine Epidermisduplikatur aus, das Velum (Ve in Abb. 8c). Entlang der Mesogloea differenzieren alle Epidermiszellen der Subumbrella, also auch die innere Hälfte des Velums die basal in den Zellfortsätzen verlaufenden Myofibrillen, die die zirkuläre SchwimmMuskulatur der Meduse bilden.

\footnotetext{
Abb. 8a-c. Interradiale Längsschnitte durch Stadien der Subumbrellarbildung bei Tripedalia cystophora. $a$ und $b$ Beginnende Einsenkung des Peristoms (PS) an der Grenze der einschichtigen Epidermis (ED) des Mundkegels (MK) und dem mehrschichtigen Körperrand mit I-Zellen (IZ); a schematisch, $b$ Schnitt durch den in a gezeigten Bereich, 5000x, Fix. 2. cSchematische Darstellung. Fortgeschrittene Einsenkung der Subumbrellarhöhle (SH), die vom Manubrium (Ma), der Subumbrella (SU) und dem Velum (Ve) begrenzt wird. Der Körperrand trägt interradial (I) die Tentakelanlagen $\left(T^{\prime}\right)$ und radial (R) die Rhopalien (gestrichelte Linie). IZ Interstitielle Zellen, N Nukleus
} 

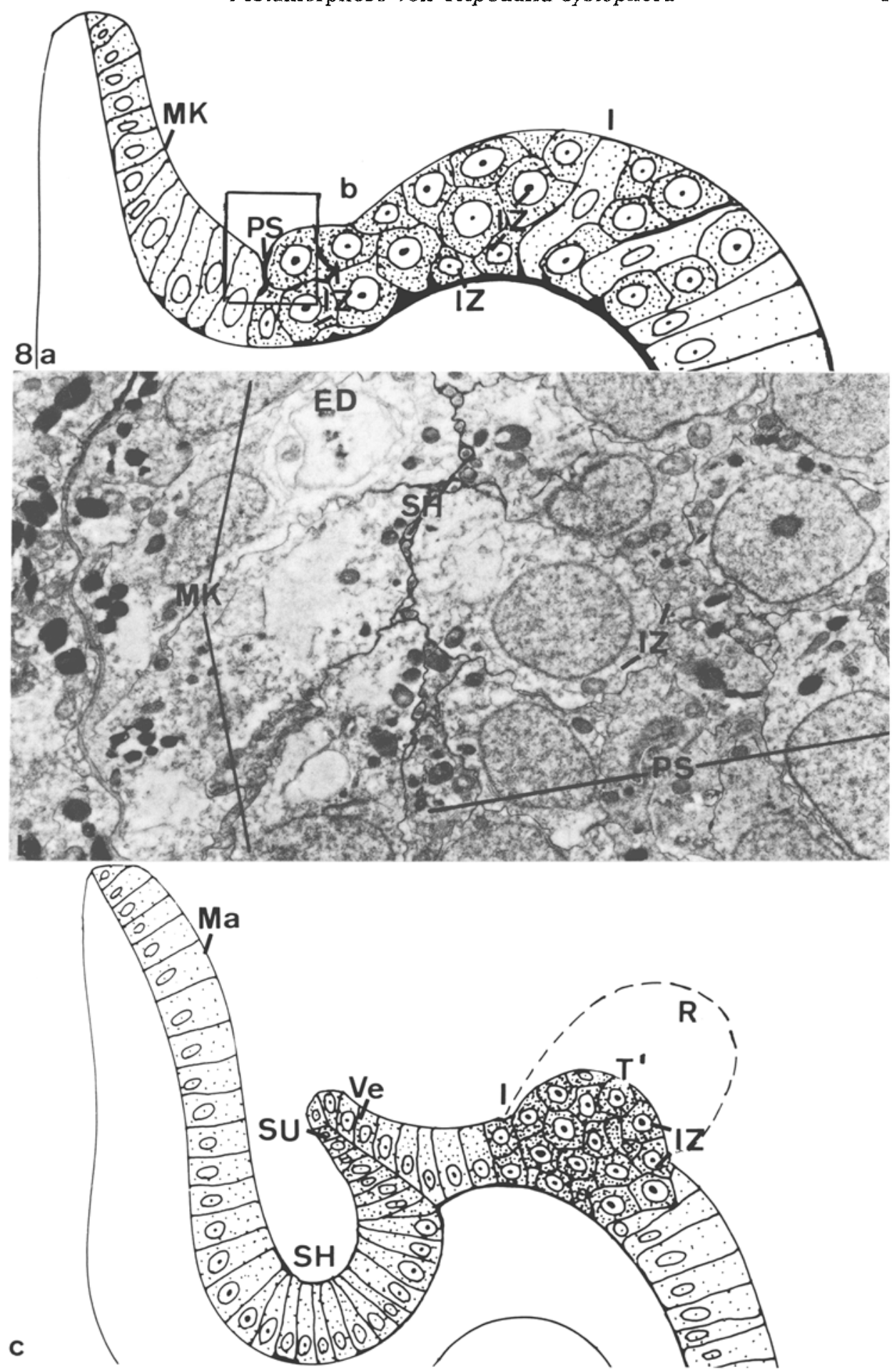


\section{Die Medusententakel}

Aus dem beschriebenen vielzelligen Bereich perioraler Epidermis, die dedifferenzierte Epithelzellen und I-Zellen enthält, entstehen die vier Interradialknospen der Medusententakel ( $\mathrm{T}^{\prime}$ in Abb. 3a und 8c). In diese hinein verlängern sich die interradialen Ränder der noch unvollständig verwachsenen Entodermlamellen bzw. Gastraltaschen. So entstehen vier hohle gastrodermal ausgekleidete Zapfen. Die Epidermis der Medusententakel besteht aus einer Vielzahl I-Zellen, jungen Epithelzellen und Cnidoblasten sowie auch Cnidocyten. Letztere werden stufenförmig über den ganzen Tentakel verteilt. Die kräftige Tentakelmuskulatur besteht aus glatten Myofibrillen. Die Gastrodermiszellen sind hochvakuolisierte Nährzellen. Erst nach der Ablösung der freischwimmenden Meduse entwickeln sich seitlich der einzelnen Tentakel noch jeweils zwei zusätzliche, gleich gebaute hohle Tentakel, die Tripedalia ihren Namen geben.

Für die Medusengestaltung ist die auf den Peristombereich konzentrierte hohe Teilungsaktivität der Zellen von besondes =r Redeutung. Ebenso wie die Mitosen ermöglicht auch die große Menge an I-Zellen die weiteren Wachstumsbewegungen. Im Gegensatz zur Exumbrella-Gestaltung, bei welcher alle beteiligten Zellen durch die Umdifferenzierung ihre neue Funktion erhalten, werden differenzierte Epithelzellen des Polypen direkt in das neu geordnete Gewebe der Subumbrella übernommen und im Laufe der Zelldifferenzierung mit zum Bestandteil der Schwimm-Muskulatur, des Velums oder der Tentakel.

\section{Morphogenese der Rhopalien}

Die bereits beschriebene Tentakelverschmelzung stellt zunächst eine Disintegration voll ausgebildeter Gewebe dar; dabei wird der Zellverband aufgelöst, so daß sich die Zellen gegeneinander bewegen können. Jedoch aggregieren auf den Quadranten nur Epidermis- mit Epidermiszellen und Gastrodermis- mit Gastrodermiszellen. In den schließlich vorliegenden Tentakelrelikten ordnen sich die Gastrodermiszellen relativ schnell zu einem einschichtigen Zellverband, der Rhopalarampulle, an. Die aus Epithelzellen, Sinneszellen und Nervenzellen bestehende Epidermis der Rhopalien und des Glockenrandes entsteht dagegen aus I-Zellaggregaten, die ihrerseits aus den dedifferenzierten Epithelmuskelzellen der Polypententakel entstanden sind. Mitosen treten während der frühen metaplastischen Vorgänge nicht auf.

\section{Umwandlung der Polypententakel zu Rhopalien}

Dedifferenzierung der Epithelmuskelzellen: Beim Einsetzen der Metamorphosekontraktion der Tentakel verlagert sich die basal in den Epithelmuskelzellen gelegene glatte Längsmuskulatur (MF in Abb. 9a) unter Verkürzung und Desorganisation bis in das Soma der Zellen. Dort treten in zunehmendem Maße Vakuolen mit heterogenem, osmiophilen Inhalt auf, die im Cytoplasma der Epithelzellen der Polypententakel fehlen. Diese Vakuolen enthalten mit fortschreitender Metamorphose immer häufiger Zellorganellen wie Mitochondrien, an welchen die Zellen deutlich verarmen, sowie die verlagerten desorganisierten Myofilamente (MF in Abb. 9b). Sie müssen deshalb als Autolysosomen (Ly in Abb. $9 \mathrm{~b}$ und c) aufgefaßt werden. Während der vakuoläre Apparat 

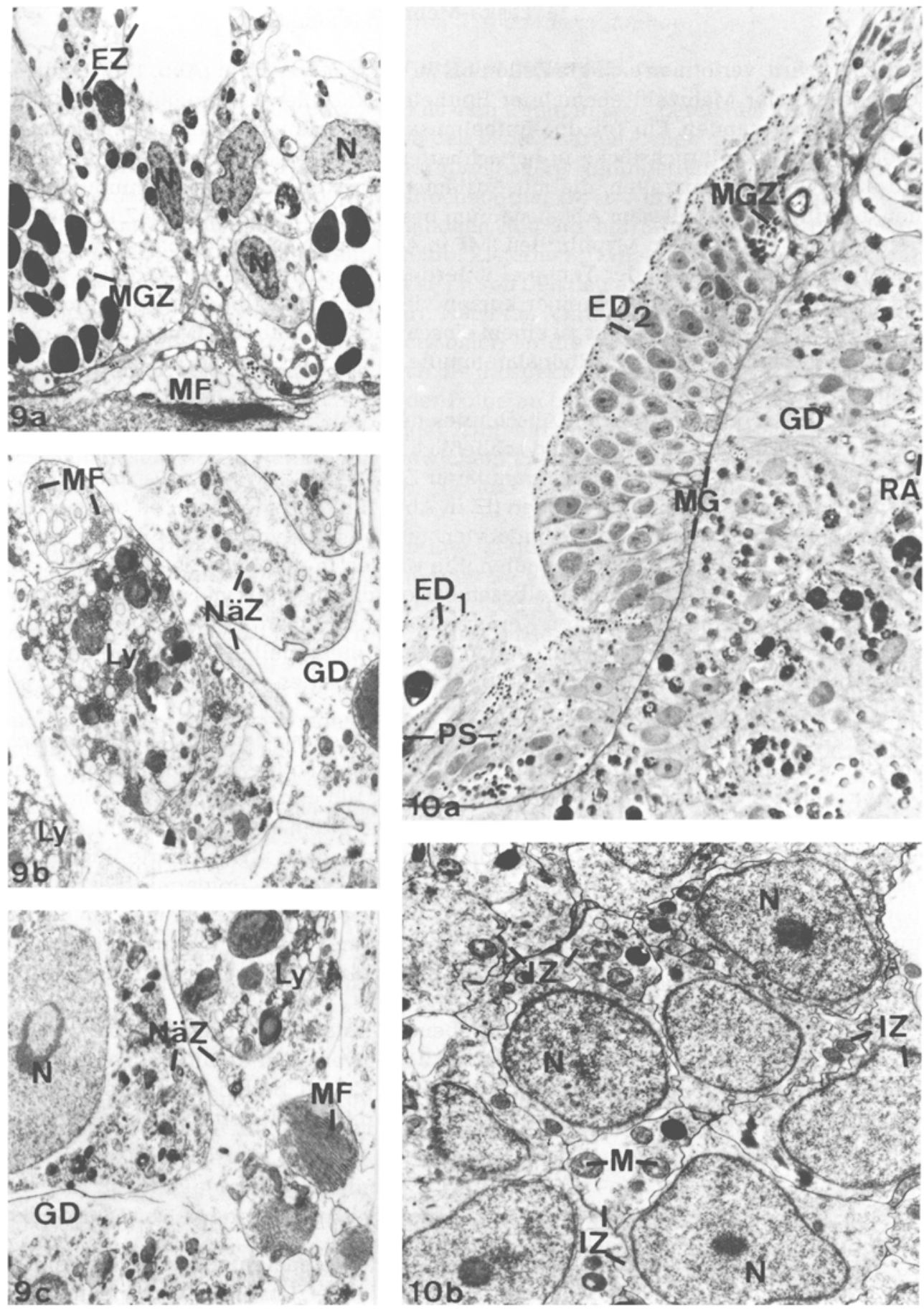

Abb. 9 und 10. Längsschnitte durch Tentakelbasen im Metamorphosestadium 1. 9a In Dedifferenzierung begriffene Epidermiszellen (EZ) mit unregelmäßig geformten Zellkernen (N), 3000x, Fix. 1. $9 b$ und $c$ Gastrodermis (GD); Nährzellen (NäZ) mit großen Lysosomen (Ly), die epidermale Myofibrillen (MF) enthalten; $b$ und $c 6500 x$, Fix 3. 10a Semidünner Längsschnitt durch die Rhopalarknospe mit Metamorphoseblastem $\left(\mathrm{ED}_{2}\right)$ in der Basis und Anlage der Rhopalarampulle (RA), 650x. ED 1 einschichtige Epidermis, MGZ Macrogranuläre Zellen, PS Peristom. 10b Metamorphoseblastem aus I-Zellen (IZ) bestehend, 6500x. Fix. 2. GD Gastrodermis, M Mitochondrien, N 
vergrößert wird, verformen sich die Zellen bis zu polygonaler Form (Abb. 10b). Schließlich sind aus der Mehrzahl ehemaliger Epithelmuskelzellen abgekugelte I-Zell-ähnliche Zellen entstanden. Ein Teil der Epithelmuskelzellen unterliegt einer vollständigen Autolyse, sodaß Zellbruchstücke in benachbarten Zellen phagozytiert werden. Hieran sind auch Gastrodermiszellen, die mit Ausläufern durch die Mesogloea hindurch reichen, beteiligt. Nur in diesem Abbaustadium besitzen die Nährzellen (NäZ in Abb. 9c) Vakuolen mit epidermalen Myofibrillen (MF in Abb. 9c). Die vom Polypen stammenden Nessel- und Nervenzellen der Tentakel unterliegen ausnahmslos der Autolyse, gehen also quantitativ verloren. Nach einer kurzen vielschichtigen Übergangsphase ordnen sich die Zellen der Gastrodermis zu einem einschichtigen Epithel (GD in Abb. 10a) rund um den Hohlraum der späteren Rhopalarampulle (RA in Abb. 10a) an, die offen mit dem Gastralraum in Verbindung steht.

In der Epidermis des basalen Abschnittes der Tentakelrelikte werden die Lysosomen kleiner, ihre Zahl nimmt ab, und schließlich fehlen sie ganz. Die Epidermis besteht nun, abgesehen von einigen macrogranulären Zellen (MGZ in Abb. 10a und 9a), aus einem Aggregat I-Zell-ähnlicher Zellen (IZ in Abb. 10b). Zur gleichen Zeit besitzen die Spitzen der Tentakelbasen noch Cnidocyten und andere typische Tentakelzellen in verschiedenen Entdifferenzierungsstadien. Sie werden in der Folge ebenfalls vollständig abgebaut. Zwischen den Tentakelbasen besteht die ebenfalls vielschichtige Epidermis des gesamten apikalen äußeren Körperrandes aus kleinen Zellen mit stark kontrastierbarem Cytoplasma und großen, runden Kernen, die auffallende Nukleoli besitzen. Diese entdifferenzierten ursprünglichen Epithelmuskelzellen werden im Folgenden als I-Zellen bezeichnet.

Zu diesem Zeitpunkt setzt die Morphogenese der Sinnesorgane ein. Die Blastemzellen zeigen zahlreiche Verzahnungen und Interdigitationen ( - in Abb. 11a) mit ihren Nachbarzellen. Typisch für alle I-Zellen (IZ in Abb. 10b und 11a) ist das ribosomenreiche Cytoplasma, wenige Dictyosomen und Mitochondrien ( $\mathrm{M}$ in $\mathrm{Abb}$. 10b). An das mehrschichtige I-Zell-Aggregat grenzt unmittelbar das noch unveränderte Epithel des Peristoms (PS in Abb. 10a). Die palisadenförmige einschichtige Epidermis ( $E D_{1}$ in $A b b$. 10a) besitzt nach wie vor große Vakuolen, basal gelegene Kerne und ein locker strukturiertes Cytoplasma. Nach Einsetzen der Metamorphose findet man eine große Zahl von Mitosestadien im Rhopalargewebe. Sie sind viel seltener auch in der Gastrodermis zu finden.

Der Unterschied zu den bisher beschriebenen Gestaltungsprozessen besteht darin, daß in der Epidermis des Tentakelreliktes alle Zellen von einer Entdifferenzierung oder Autolyse erfaßt werden. Die vielschichtige, aus I-Zellen bestehende Epidermis der Rhopalarknospe stellt ein Blastem dar, in dem keine differenzierten Polypenzellen mehr vorhanden sind.

\section{MORPHOGENESE DER LICHTSINNESORGANE}

In der ursprünglichen Tentakelbasis ist die Entdifferenzierung aufgrund des spitzenwärts gerichteten Fusionsgradienten schon vor den letzten Abbauvorgängen in den Tentakelspitzen abgeschlossen. Zu diesem Zeitpunkt beginnt im körpernahen Teil der Tentakelrelikte bereits die Neudifferenzierung, in deren Verlauf median zwei Linsenaugen und lateral je zwei Grubenaugen auf jeder der vier Rhopalarknospen entstehen. 


\section{Differenzierung der Retinazellen}

Auf der Medianlinie der Rhopalarknospen treten in zwei Bereichen Gruppen von IZellen (IZ in Abb. 11a) auf die sich von den benachbarten Zellen durch ihre wellenförmige Oberfläche ( in $\mathrm{Abb}$. 11a) bei gleichzeitig verändertem Organellenbestand unterscheiden. Zahl und Größe der Mitochondrien ( $M$ in Abb. 11a und b) nehmen zu. Das ursprünglich nur in Einzahl vorhandene und aus nur zwei Zisternen bestehende Dictyosom besitzt nun durchschnittlich fünf Zisternen ( $D$ in Abb. 11a). Auch die Anzahl von Dictyosomen pro Zelle verdoppelt sich. Von den neu entwickelten Golgi-Zisternen werden zahlreiche Vesikel abgeschnürt. Nach der Verlagerung der nun regelmäßig in Zweizahl vorhandenen kernnahen Dictysomen an die beiden Zellpole setzt eine Zellstreckung ein ( $\mathrm{Abb}$. 11a und b), wodurch die prospektiven Retinazellen ( $R Z$ in Abb. 11b) entstehen. Ihr Cytoplasma verarmt in der Folge an freien Ribosomen, die das I-Zellstadium (Abb. 11a) prägten. Die in geringer Zahl vorhandenen, relativ kleinen Zisternen des endoplasmatischen Retikulums entwickeln sich zu einem weitläufigen Netz. Und der zunächst kugelige Kern ( $\mathrm{N}$ in Abb, 10b und 11a) folgt der Zellstreckung und wird eiförmig.

In den peripher um die Sinneszellen liegenden prospektiven Epidermiszellen entstehen nahe dem ovalen Kern kleine zentrale Vakuolen und wenige Mitochondrien. Diese Zellen ordnen sich zu einem einschichtigen Epithel an, das die gesamte Rhopalaroberfläche einschließlich der noch nicht differenzierten I-Zellen bedeckt.

Nach ihrer Streckung sind die prospektiven Retinazellen einschichtig vertikal zur Mesogloea angeordnet und kleiden dann zwei flache Gruben, die Vorläufer der Linsenaugen, aus. Das sie umgebende Blastem bleibt vielschichtig. Die durch die Streckung entstandenen Zellpole sind nicht gleichförmig: an die Grube grenzt der schmale Apikalteil der prospektiven Retinazellen, während der Mesogloea die verbreiterte Zellbasis mit dem Kern ( $\mathrm{N}$ in Abb. 11b) aufsitzt. Diese einschichtige Anordnung wiederholt sich ebenso im großen und auch im kleinen Grubenauge. Vom apikalen Dictyosom werden die vesikulären Untereinheiten der Pigmentvakuolen abgeschnürt. Ihr Inhalt ist osmiophil und zeigt eine tubuläre Struktur. Der basal gelegene Golgi-Apparat (D in Abb. 12a) ist dagegen von zahlreichen, wenig kontrastierbaren Vesikeln umgeben. Wenige Querschnitte zeigen bereits auf dieser Entwicklungsstufe der Lichtsinnesorgane zu Neuriten verlängerte Zellbasen ( $\mathrm{Ne}$ in Abb. 12a und b) mit Neurotubuli (NT in Abb. 12b).

\section{Ciliogenese}

Die Cubozoen entwickeln sowohl in den Linsen- als auch in den Grubenaugen ausschließlich einen Grundtypus von Retinazellen: Es handelt sich um langgestreckte, primäre Sinneszellen, die neben den Sehpigmenten und einem ableitenden Neuriten auch die Schirmpigmente enthalten. Am grubennahen Pol zur Oberfläche des Rhopaliums hin gerichtet, entwickeln die Sinneszellen je ein Cilium. Die frühe Centriolaranlage (Ce in Abb. 13a) liegt zwischen Kern und apikalem Golgi-Apparat. In direkter Verbindung mit diesem Centriol wird ein zunächst aus granulärem Material ( ${ }^{*}$ in Abb. 13a) bestehendes Satellitencentriol ( $\mathrm{pCe}$ in Abb. 13b) synthetisiert. Proximales wie auch distales Centriol besitzen das $9 \times 3$-Tubuli-Muster und orientieren sich in der Zellperipherie rechtwinklig zueinander (Abb. 13b). Der Basalkörper ist über radiär von den Mikrotubuli fortziehende Mikrofilamente (MFi in Abb. 13e) an der Zellmembran fixiert. 

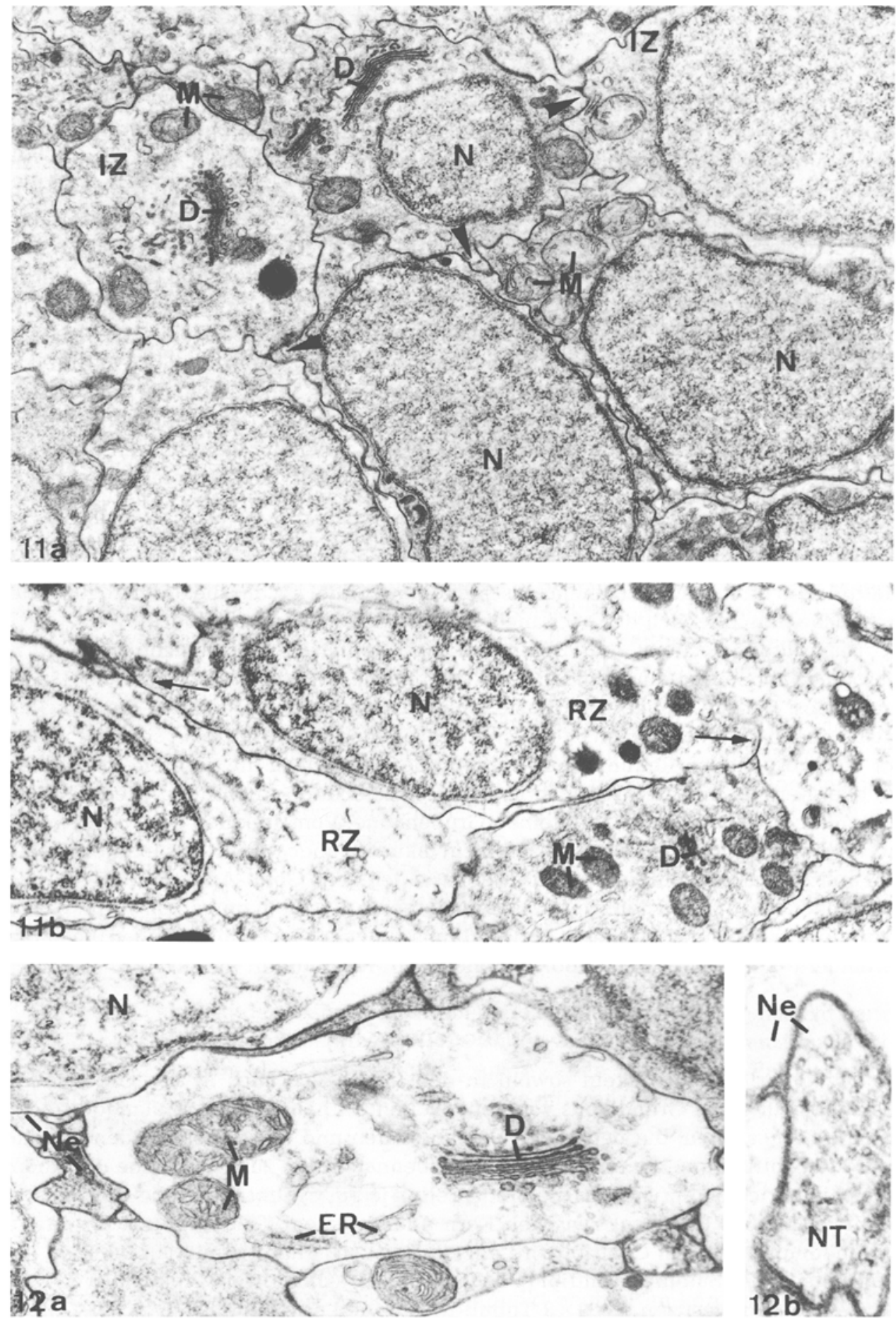

Abb. 11 und 12. Differenzierung von Retinazellen von Tripedalia cystophora. 11a und b Junge IZellähnliche Retinazellen (IZ) mit eiförmigen Zellkernen (N), wellenförmiger ( ) Oberfläche und Dictyosomen (D); $a 13$ 400x. $b$ Prospektive Retinazellen (RZ) im Streckungswachstum $(\rightarrow$ ), 13 400x; je Fix. 1. 12a und $b$ Junge Retinazellen mit benachbarten Neuriten (Ne), $a 26000 \mathrm{x}, b 80000 \mathrm{x}$; Fix. 4 . D Dictyosom, ER Endoplasmatisches Retikulum, M Mitochondrium, NT Neurotubuli 

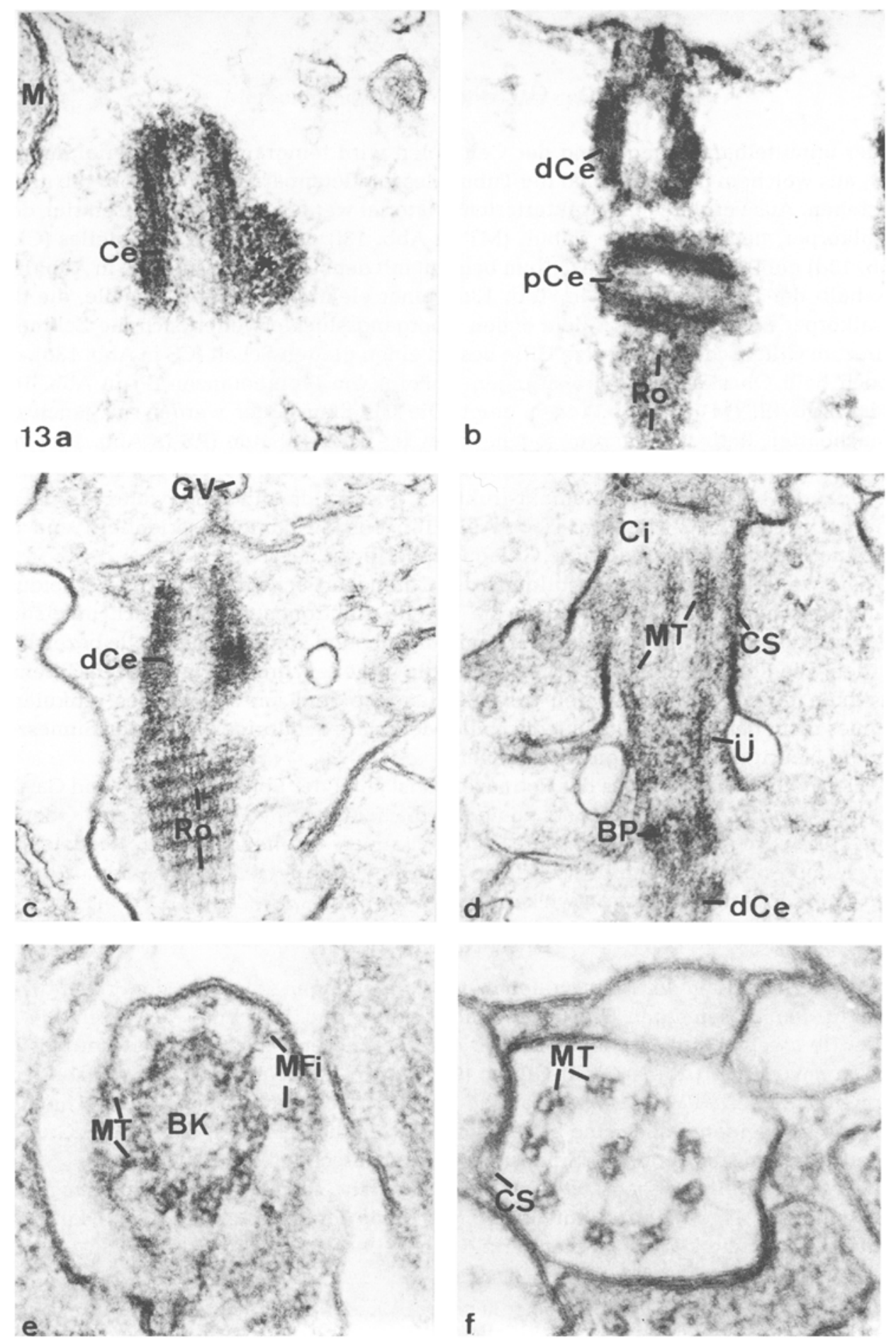

Abb. 13a-f. Schnitte durch aufeinanderfolgende Entwicklungsstadien sich differenzierender Sinnescilien bei Tripedalia cystophora. a Centriol (Ce) mit benachbartem globulären Material (*). $85000 x . b$ Rechtwinklige Anordnung von distalem und proximalem Centriol (p/dCe) am Zellapex und granulär strukturierte Rootletanlage (Ro), $60000 \mathrm{x}$. CQuergestreifter kurzer Rootletapparat (Ro), $85000 \mathrm{x}, d$ Junge Cilienanlage; auf das distale Centriol (dCe) folgt die Basalplatte (BP), das Ubergangsstück (U) und der Cilienschaft (CS) mit den Mikrotubuli (MT), 65 000x. e Verankerung des Basalkörpers (BK) an der Zellmembran durch Mikrofilamente (MFi) 60 000x. $f$ Sinnescilium quer mit $9 \times 2+2$-Struktur, $80000 x$. Alle Fix. 2. GV Golgivesikel 
In der unmittelbaren Umgebung der Centriolen wird feingranuläres Material angelagert, aus welchem nach proximal die Tubuli des Rootletapparates (Ro in Abb. 13b und c) entstehen. Aus vergleichbar strukturiertem Material werden vom distalen Centriol, dem Basalkörper, nach apikal die Tubuli (MT in Abb. 13f) des äußeren Cilienteiles (Ci in Abb. 13d) gebildet. Das äußere Cilium beginnt mit dem Übergangsstück (Ü in Abb. 13d) oberhalb der Basalplatte (BP in Abb. 13d), einer elektronendichten Lamelle, die den Basalkörper abschließt. Nach dem engen Übergangsstück erweitert sich die Zellmembran zum Cilienschaft. Die kurze Cilie besitzt einen glatten Schaft (CS in Abb. 13d), der jedoch bald Oberflächenvergrößerungen in Form von Protuberanzen ( $\mathrm{Pr}$ in Abb. 14b) und Mikrovilli (MV in Abb. 14a-c) zeigt. Die Cilienausläufer werden mit jenen der benachbarten Retinazellen zum sogenannten retikulären Saum (RS in Abb. 14b) verflochten. Kennzeichnend für den Mikrovillisaum ist der enge Kontakt der Membranen, die einander berühren, ohne Kontaktstrukturen auszubilden. In den erweiterten Cilienschäften ist das $9+2 *$ Muster (MT in Abb. 14b und c) häufig desorientiert; und die einzelnen Mikrotubuli sind in die Cílienperipherie verlagert.

Die weitere spezifische Ausbildung der Cilienoberfläche führt zur Unterscheidung dreier verschiedener Rezeptortypen, die bereits elektronenmikroskopisch untersucht sind, und historisch als Prismazelle, Pyramidenzelle und lange Pigmentzelle bezeichnet werden. Die Retinazellen des Becherrandes, die Iriszellen, grenzen mit kurzen Cilienrudimenten direkt an die äußeren Linsenzellen. Sie sind am Aufbau des retikulären Saumes nicht beteiligt, besitzen jedoch alle Merkmale der übrigen bipolaren Sinneszellen wie Neurit und auch Pigmentvakuolen.

Dem Ciliogenese-Modus der Retinazellen ist jener der Epidermiszellen und Gastrodermiszellen des Medusenkörpers analog. Jedoch zeigen die Flagellen keine Oberflächenerweiterungen und ragen ohne Verflechtungen in offene Räume. Rootlets sind selten, doch sind sie ebenfalls Merkmale derjenigen Körperzellen, die auch außerhalb von Sinnesorganen Neurite entwickeln und somit Sinneszell-Charakter besitzen.

\section{Die Grubenaugen}

Die Entwicklung der Retinazellen in den Grubenaugen entspricht der Frühentwicklung in den Linsenaugen. Nach der Polarisierung und Streckung der interstitiellen Zellen in zwei Regionen beiderseits der Medianlinie entstehen primäre Sinneszellen vom Prismazelltyp (Abb. 14) mit Cilium (Ci in Abb. 14a), Neurit (Ne in Abb. 14a) und Pigmentvakuolen (PV in Abb. 14a und c). Die Grubenaugen sind unterschiedlich geformt: die beiden großen sind bohnenförmige, längliche Flecke; die kleinen Grubenaugen dagegen sind rund. Die Sinnesgruben sind ausschließlich von Cilien und Mikrovilli ausgefüllt. Im Gegensatz zum radiärsymmetrischen kleinen Grubenauge mit gleichmäßiger Pigmentation entwickelt das große Grubenauge an einer Hälfte der Grube randständig stärker pigmentierte Retinazellen.

Abb, 14a-c. Differenzierungsstadien einer Retinazelle von Tripedalia cystophora. a Schematische Darstellung der Differenzierung einer I-Zelle (IZ) durch Streckungswachstum, Pigmententwicklung, Ausbildung eines Ciliums (Ci) und eines basalen Neuriten (Ne). b Längsschnitt durch den erweiterten Cilienschaft (CS) einer Prismenzelle, dessen Oberfläche durch Protuberanzen (Pr) und Mikrovilli (MV) erweitert ist, $41000 \mathrm{x}$, Fix. 1. CQuerschnitt durch Cilienschäfte (CS) und Mikrovilli (MV), 40 000x, Fix. 1. BK Basalkörper, MT Mikrotubuli, MV Mikrovilli, N Nukleus, PV Pigmentvakuole, RS retikulärer Saum, RZ Retinazelle, Ü Übergangsstück 

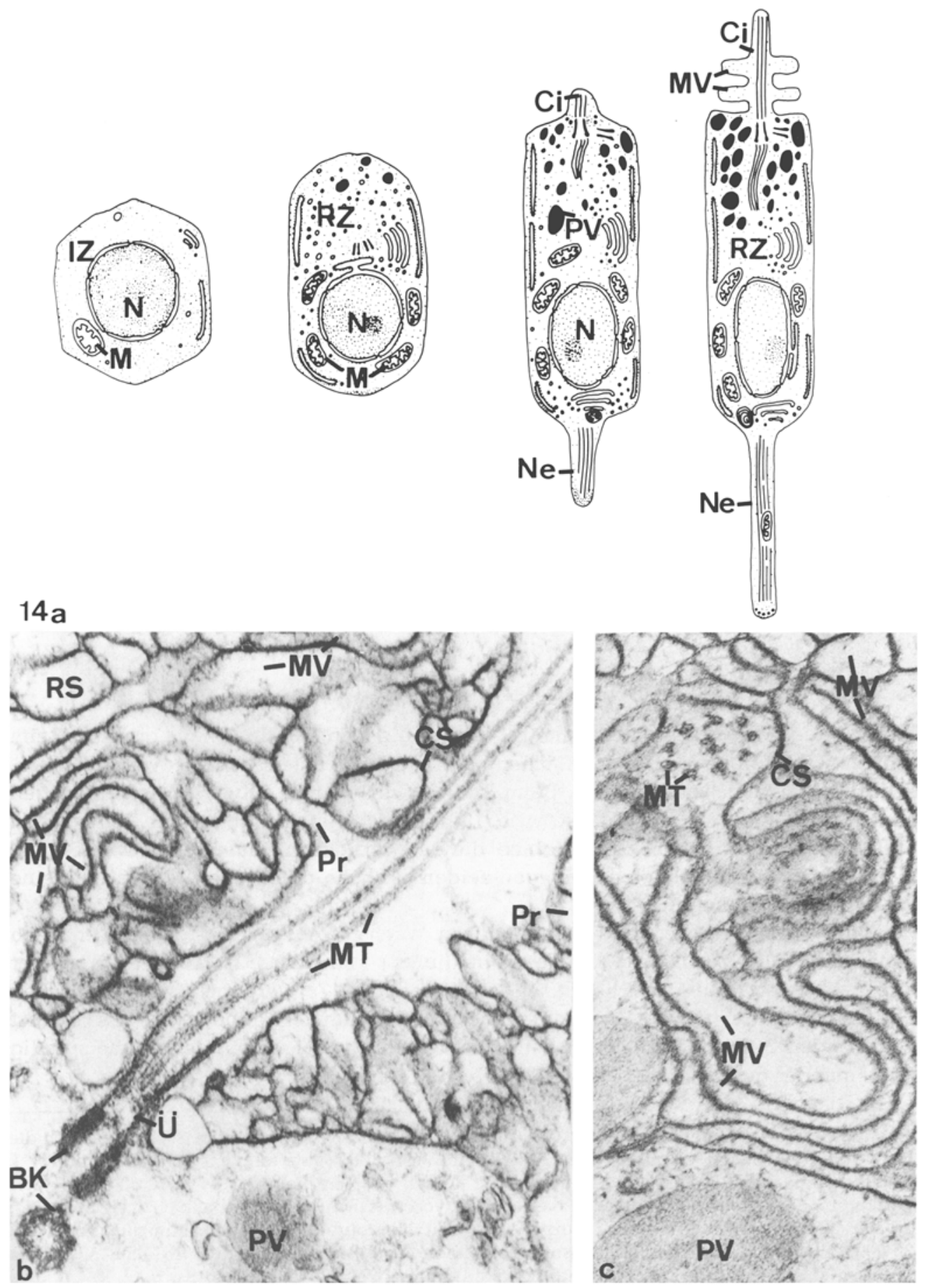


\section{Neuritengenese}

Sobald die Linsenaugen-Anlagen der Medianlinie so wie auch die seitlichen Grubenaugen durch ihre Pigmentierung und Einsenkung erkennbar werden, entsteht ein Geflecht von Zellausläufern basal von den Retinazellen. Es liegt der Mesogloea direkt an und verbreitert sich mit fortschreitender Differenzierung und Zunahme der Retinazellzahl in den Augen. Es handelt sich um die sprossenden Neurite der Sinnes- und Nervenzellen. Der Neurit der Rezeptorzellen (RZ in Abb. 15a) wird basal von einem sogenannten Wachstumshügel (" in Abb, 15a) aus gebildet, dessen Cytoplasma eine zunehmende Zahl vesikulärer Elemente enthält, die Abkömmlinge des Golgi-Apparates und/oder des endoplasmatischen Retikulums (ER in Abb. 15a) darstellen. Der Inhait der Vesikel ist wenig osmiophil und kaum kontrastierbar; feingranuläres Material von Ribosomengröße konzentriert sich in der basalen Ausbuchtung der Zelle, dem Wachstumshügel. Von hier aus differenziert sich der Neurit (Ne in Abb. 15b und c). Er enthält Mikrotubuli (NT in Abb. 16a) sowie auch Mikrofilamente, die vor einem ungeordneten Geflecht aus osmiophilem Material am Wachstumspol enden. Die Neurotubuli sind parallel zur Wachstumsrichtung orientiert und begleiten den Neuriten auch im ausdifferenzierten Zustand. Zisternen des endoplasmatischen Retikulums sind selten, Mitochondrien ( $\mathrm{M}$ in Abb. 16a) dagegen häufig. Regelmäßiger Bestandteil der Basis der Sinneszellen sind auch die multilamellären Körper (MLB in Abb. 16b), die im Zentrum der Dictyosomen (D in Abb. 16b) entstehen. Die im Anschnitt spiralig gewundenen Membranstapel können die Größe von Dictyosomen übersteigen. Die Funktion der multilamellären Körper ist bisher unklar. Sie verbleiben stationär im Perikaryon und sind nie in den Neuriten zu finden.

\section{Differenzierung der Linsen- und Corneazellen}

Die lentigenen Zellen entstehen aus I-Zellen, die an die Retinaanlage grenzen. Beim großen Linsenauge sind das oberflächennahe I-Zellen aus dem Bereich zwischen Statolith und Retinabecher (Abb. 17). Beim kleinen Linsenauge entwickeln sich dagegen Mesogloea-nahe I-Zellen zur Linse (Abb. 18). Den sich gleichzeitig mit den Retinazellen abflachenden lentigenen Zellen fehlen die Merkmale von Sinneszellen wie Cilium, Neurit und Pigmentvakuolen. Dagegen zeigen sie hohe mitotische Aktivität, die eine Wachstumsbewegung auslöst.

Beim großen Linsenauge verläuft diese Wachstumsbewegung der Linsenzellen zunächst parallel zur Längsachse des Rhopaliums $(\rightarrow$ in Abb. 17c). Am Becherrand der überwachsenen Grube von Retinazellen ( $R Z$ in $A b b, 17 c)$ verformen sich die flachen Zellen und ändern ihre Wachstumsrichtung zum Zentrum der Retina hin. Die zu vorderst wachsenden Zellen bilden damit den Mittelteil für die folgenden Zellen, die spiralig übereinander gelagert die Linse ( $\mathrm{L}$ in $\mathrm{Abb}$. 19) formen.

Abb. 15 und 16. Differenzierung der Neurite bei Tripedalia cystophora. Längsschnitte durch die Basis von Retinazellen. a Junge Retinazelle (RZ) im Vesikulationsstadium mit Wachstumshügel ("), $22000 \mathrm{x}$, Fix 2. b Retinazelle (RZ) mit einem kurzen basalen Neuriten (Ne), $10000 x$, Fix. 1. C Perikaryon einer Retinazelle (RZ) mit basalem Dictyosom (D) und Golgivesikeln (GV), $15500 x, F i x$. 2. 16a Distaler Abschnitt eines Neuriten (Ne) mit Neurotubuli (NT) und Mitochondrien (M), $26000 x$, Fix. 1. $b$ Vom basalen Dictyosom abstammende multilamelläre Körper (MLB), $11000 x$, Fix.

1. ER endoplasmatisches Retikulum, N Nukleus, Ne Neurit 

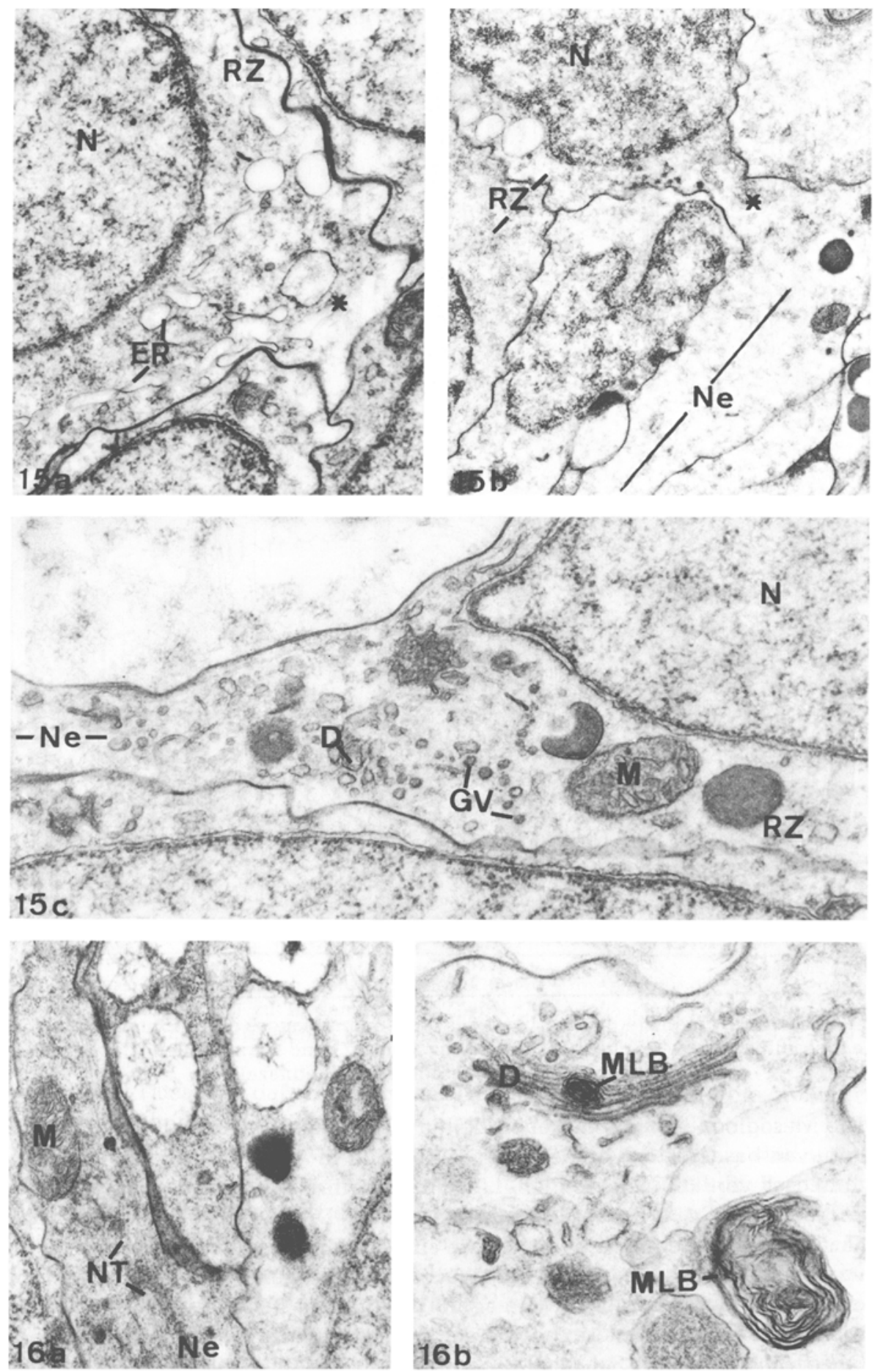


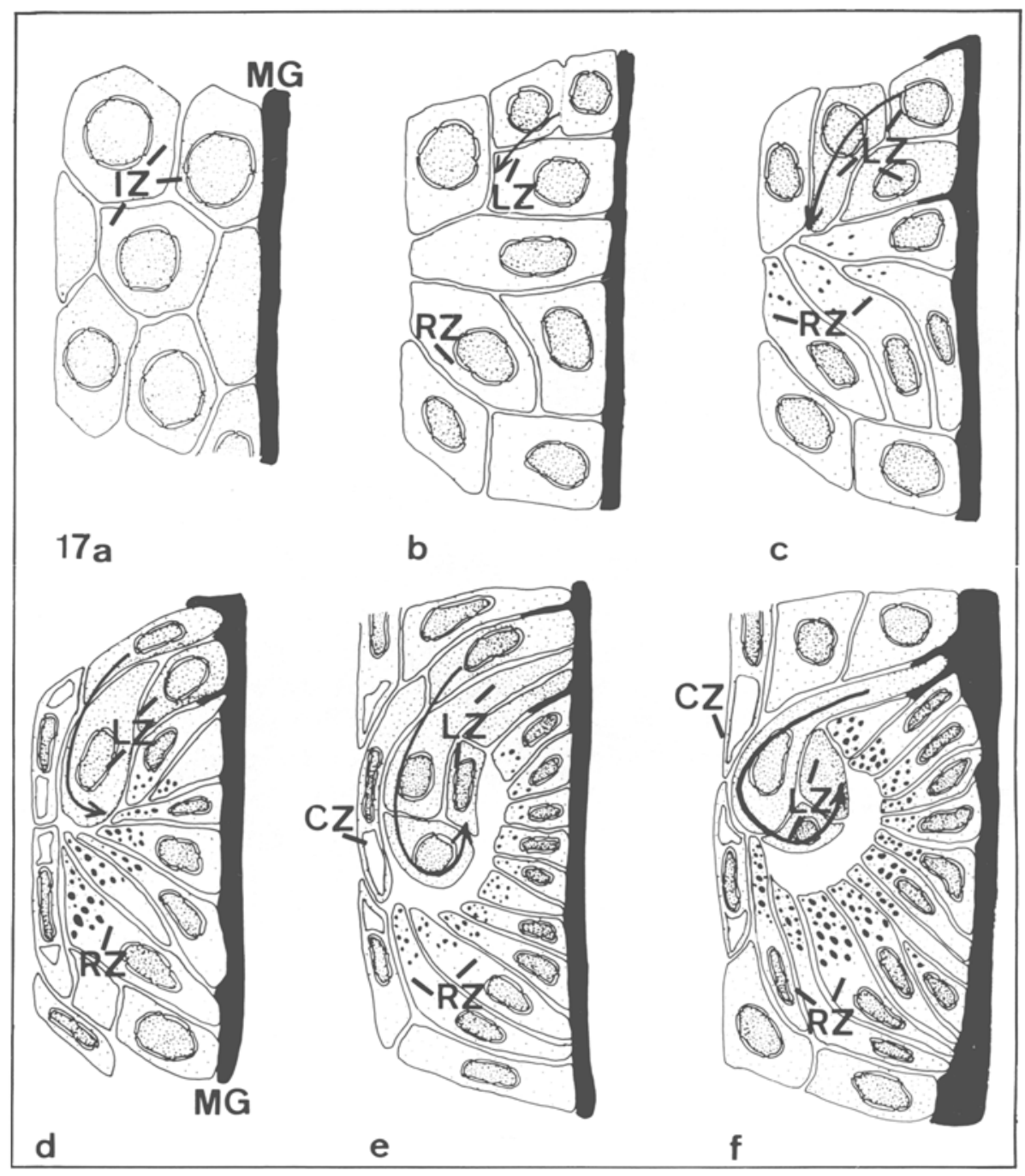

Abb. 17. Schema: Differenzierung der Linse des großen Linsenauges durch Einrollung $(\rightarrow)$ oberflächennaher teilungsaktiver Zellen (IZ) zu Linsenzellen (LZ) und Corneazellen (CZ) bei Tripedalia cystophora. MG Mesogloea, RZ Retinazelle

Die Mesogloea-nahen lentigenen Zellen ( $\mathrm{LZ}$ in Abb. 18b) des kleinen Linsenauges wachsen von basal seitlich an den Retinazellen ( $R Z$ in $A b b .18 \mathrm{c}$ ) entlang. Dabei ändern die zunächst vertikal wachsenden Linsenzellen ihre Wachstumsrichtung in einem Bogen ( $\rightarrow$ in Abb. 18d-f) zu den Retinazellen hin. Die Linsenzellen wachsen an den Retinazell-Apices entlang und überlagern sich spiralig wie auch die Zellen im großen Linsenauge. Das Ausgangsareal der Wachstumsbewegung, die Linsenbasis, behält seinen Kontakt zur Mesogloea (MG in Abb. 18 und 19). Daher entsteht keine kugelige Linse, sondern eine keulenförmige, die den Augenbecher und seine zunächst senkrecht zur Oberfläche stehende Sehachse (A in Abb. 19) verschiebt. Daraus erklärt sich die 


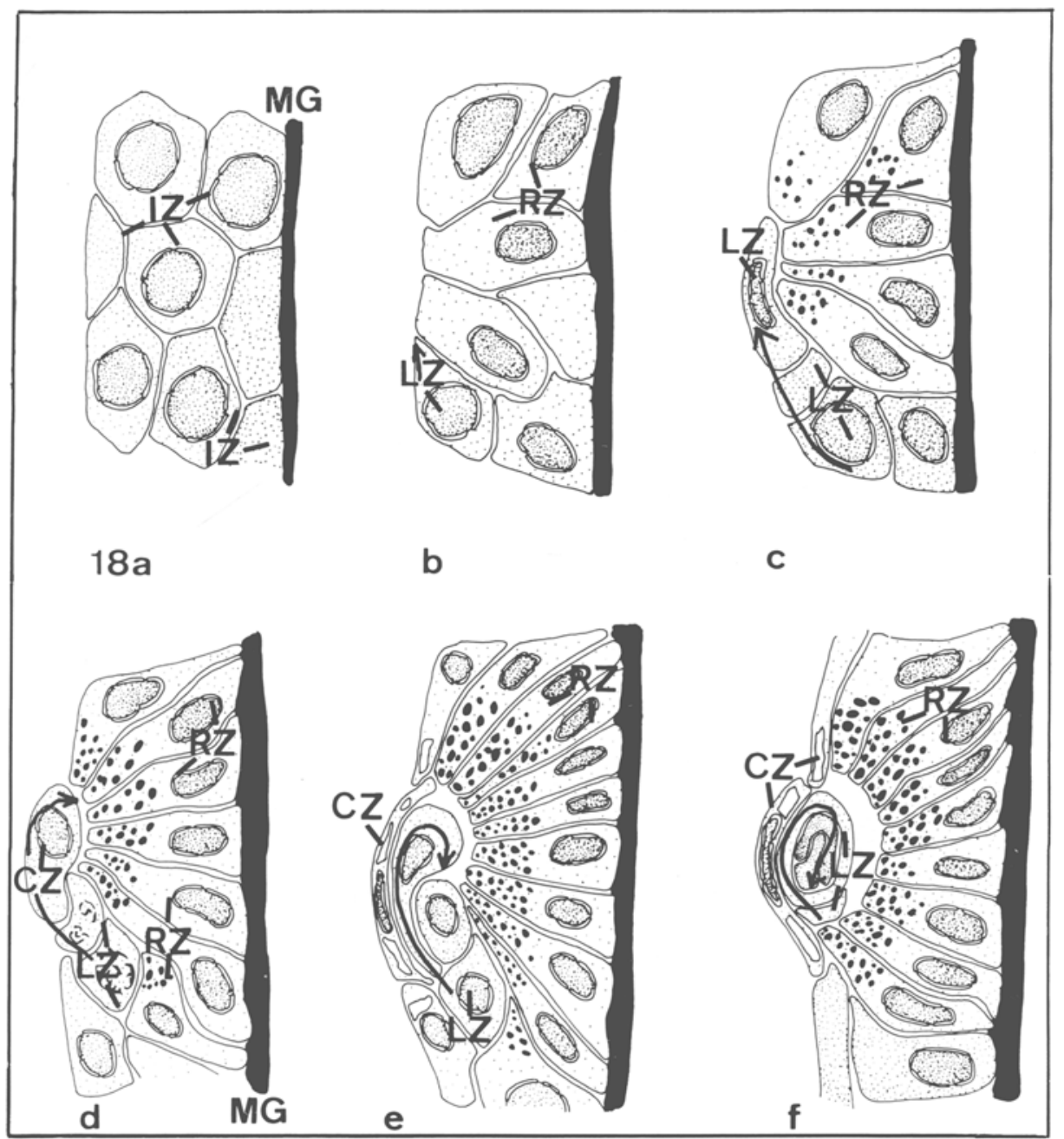

Abb. 18. Schema: Differenzierung der Linse des kleinen Linsenauges durch Einrollung $(\rightarrow)$ Mesogloea-naher Zellen (IZ) zu Linsenzellen (LZ), bei Tripedalia cystophora. Differenzierung epidermaler Zellen zu Corneazellen (CZ). RZ Retinazelle

ungewöhnliche Tatsache, daß bei adulten Tieren die Sehachsen von großem und kleinem Linsenauge nahezu senkrecht aufeinander stehen (Abb. 19).

Die Differenzierungs- und Alterungsvorgänge in den Linsenzellen sind während der Linsenmorphogenese in beiden Linsenaugen identisch. Während der Formungsbewegung zeigen die jungen Linsenzellen zahlreiche Zellausläufer und ein organellenarmes Cytoplasma. Nach Überlagerung mehrerer Linsenzellen fehlen zunächst die Zellprotuberanzen. Bei fortschreitender Abkugelung der Linse nimmt die Strukturdichte des Cytoplasmas zunächst in den inneren, älteren Zellen der Linsenanlage deutlich zu. Es handelt sich um feingranuläres, osmiophiles Material, das die Zellen dicht ausfüllt. Der Kern zeigt Rupturen seiner einheitlichen Hülle und entspricht nach der Fixierung in 


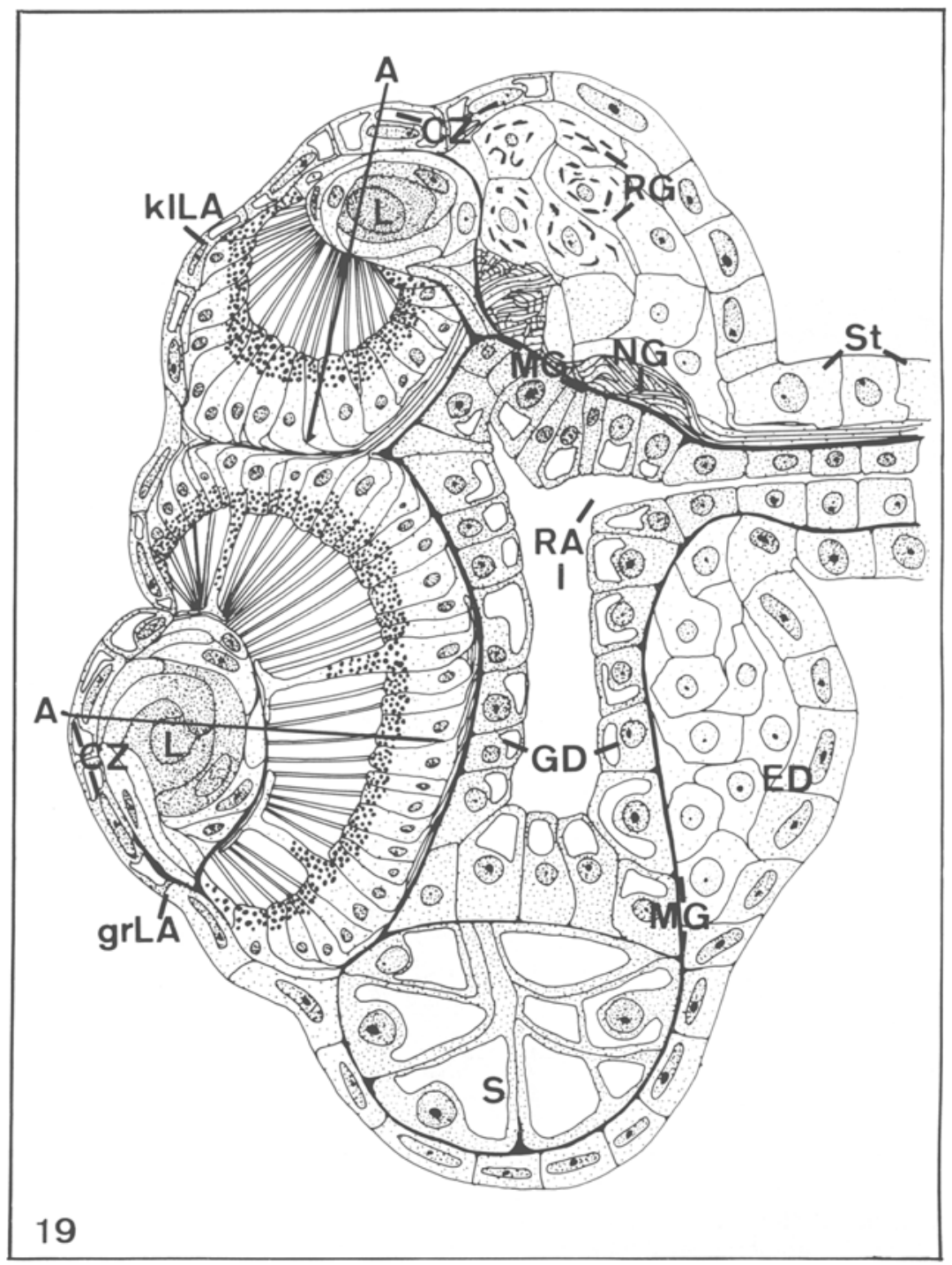

Abb. 19. Tripedalia cystophora. Längsschnitt durch ein ausdifferenziertes Rhopalium mit großem und kleinem Linsenauge (gr/kILA), deren Sehachsen (A) senkrecht aufeinander stehen; mit Statocyste (S) am Ende der Rhopalarampulle (RA) und dem epidermalen Nervengeflecht (NG), in welches das Rhopalarganglion (RG) integriert ist. CZ Corneazelle, ED Epidermis, GD Gastrodermis, L Linse, MG Mesogloea, St Stiel

Struktur und Kontrastierbarkeit dem umgebenden Cytoplasma. Ebenso wie der perinukleäre Spalt sind die Mitochondriencristae aufgebläht. Diese Veränderung schreitet vom Zentrum der Linse nach außen hin fort. Die äußere Lage der Linse wird von diesem Prozeß nicht betroffen. Sie sezerniert zusammen mit den Corneazellen das Linsenkapselmaterial, das in Struktur und Osmiophilie dem granulären Anteil der Mesogloea entspricht. Jene Linsenzellen, die an den retikulären Saum angrenzen, bilden kurze 
Fortsätze, die mit den Cilien und Mikrovilli ein Geflecht bilden. Ihnen gegenüber verschließen einschichtig Corneazellen ( $\mathrm{CZ}$ in $\mathrm{Abb}$. 19) die Linsenaugenanlage. Corneazellen unterscheiden sich von den benachbarten Epidermiszellen lediglich durch ihre abgeflachte Form und den Besitz einer großen zentralen Vakuole. Die Linse des großen Linsenauges (grLA in Abb. 19) besitzt bei der Jungmeduse durchschnittlich 4-6 Zellagen, deren Cytoplasmadichte von innen nach außen abnimmt, was ebenso für das kleine Linsenauge (klLA in Abb. 19) zutrifft. Jedoch unterscheiden sich die Formen der Linse aufgrund ihrer Entstehungsgeschichte: die große Linse ist asymmetrisch bikonvex, die kleine Linse ist tropfenförmig.

\section{Morphogenese der Schweresinnesorgane}

Die Statocysten (S in Abb. 19 und 20a) sind in sich geschlossene, mehrzellige Einheiten, die an der Spitze der gastrodermalen Rhopalarampulle (RA in Abb. 20a) liegen. Es handelt sich um Lithocyten, die in großen Vakuolen (Va in Abb. 20a und b) Kristallstrukturen enthalten. Nach röntgen-spektroskopischen Untersuchungen bestehen die Kristalle aus einem hohen Calcium- und Schwefelanteil, der an eine organische Matrix gebunden ist. Sobald die Tentakelbasis nach der Einschmelzung der Polypententakel einen gastrodermalen Hohlraum, die Rhopalarampulle, besitzt, der einschichtig von Nährzellen ausgekleidet wird, bildet sich eine Mesogloealamelle zwischen wenigen Zellen der Rhopalarspitze und den übrigen Zellen des Hohlraumes. Im Gegensatz zu den zylindrischen Nährzellen sind die prospektiven Lithozyten kubisch und bilden jeweils eine große Vakuole aus. Die Zellen sind durch zahlreiche Interdigitationen ( in $\mathrm{Abb} .20 \mathrm{c}$ ) miteinander verzahnt. Lithozyten ( $\mathrm{LC}$ in $\mathrm{Abb} .20 \mathrm{~b}$ und $\mathrm{c}$ ) enthalten neben einem runden, nukleolushaltigen Kern ( $N$ in $\mathrm{Abb}$. 20c) Mitochondrien ( $\mathrm{M}$ in $\mathrm{Abb} .20 \mathrm{~b}$ ) und Dictyosomen ein auffallend gut ausgebildetes endoplasmatisches Retikulum (ER in $\mathrm{Abb} .20 \mathrm{~b}$ ). Dieses liegt zunächst in vesikulärer Form (Abb. 20b) vor; und zahlreiche kleine Vakuolen ( $\mathrm{Va}^{\prime}$ in $\mathrm{Abb} .2 \mathrm{~b}$ ) nahe dem endoplasmatischen Retikulum gleichen in ihrem Inhalt dem der großen Vakuole (Va in Abb. 20c).

Nach morphologischen Kriterien werden als Rezeptoren des Schwerereizes jene Sinneszellen (SZ in Abb. 21) der Rhopalaroberfläche angesehen, die außerhalb der Lichtsinnesorgane liegen und bei der Rhopalarbewegung in den Sinnesnischen mit ihren Cilien die exumbrellare Oberfläche (EU in Abb. 21) berühren. Diese primären Sinneszellen entstehen aus I-Zellen nach dem beschriebenen Modus und besitzen basal vom Cilium ein Rootlet (Ro in Abb. 21) sowie einen Neuriten (Ne in Abb. 21).

\section{Morphogenese des Nervensystems}

Gleichzeitig mit den Sinnesorganen entsteht während der Metamorphose ein neues Nervensystem. Dem Polypen-Nervennetz vergleichbar liegt in der Glocke ein diffuses Nervennetz aus Neuronen vor. Je nach ihrer Lage kann man Motoneurone mit neuromuskulären synaptischen Endigungen und Interneurone mit somatischen Synapsen unterscheiden. Cytologisch und ontogenetisch besteht jedoch in den Perikarien kein Unterschied. Für Cubomedusen charakteristisch entwickelt sich zusätzlich am Glockenrand ein subumbrellarer Ringnerv, der über vier radiale Stielnerven mit den Rhopalien in Verbindung steht. Letztere enthalten die Rhopalarganglien, die als Schrittmacher für die Schwimmbewegung dienen. 


\section{Differenzierung von Inter- und Motoneuronen}

Multipolare Nervenzellen (NZ in Abb. 22a), die als Interneurone an mehrere Sinneszellen grenzen und außerdem mit den Ganglienzellen im Rhopalium synaptisch verschaltet sind, entwickeln sich in der Regel vor der vollständigen Ausbildung der Retinazellen. Auch nach der Anlage der Linsenaugen werden noch zusätzlich Nervenzellen aus I-Zellen differenziert, die Kontakte zu mehreren Retinazellen besitzen. Nach der bereits beschriebenen Vesikulationsphase und der Streckungsphase der Sinnesbzw. Nervenzellen wachsen die Neurite aus. Sie sind entweder kurz und grenzen an die Nachbarzellen oder lang und beteiligen sich an der Bildung des Nervengeflechtes. Die Neuritengenese verläuft bei allen primären Sinneszellen und Nervenzellen gleich.

\section{Der Ringnerv}

Die Motoneurone (NZ in Abb. 22a und b) der Subumbrella (SU in Abb. 22a und b) und des subumbrellaren Ringnerven differenzieren sich aus I-Zellen der epidermalen Velarbasis. In ihrer frühen Wachstumsphase enthalten die Neurite ( $\mathrm{Ne}$ in $\mathrm{Abb} .22 \mathrm{~b}$ ) dieser Zellen osmiophile Grana, deren Durchmesser mehr als $180 \mathrm{~nm}$ beträgt und die in den Neuronen der Rhopalien fehlen. Solange am Rhopalium noch kein Rhopalarstiel und somit auch kein Stielnerv vorhanden ist, grenzen die Interneurone und Motoneurone der Ringnervanlage in den Radien direkt aneinander (Abb. 22a). Eine Verbindung ex- und subumbrellarer Zellen durch die Mesogloea (MG in Abb. 22a) ist hier möglich, da im Bereich der radialen Sinnesnischen und der Basis des Velums der Glockenrand keine gastrodermalen Elemente enthält und somit die Epidermislagen von Exumbrella und Subumbrella einander anliegen. Während sich die Epithelmuskelzellen differenzieren und der Rhopalarstiel auswächst, verlängern sich auch die Neurite und bilden den Stielnerv. Die Perikarien der Nervenzellen werden in das exumbrellare Rhopalium und in den subumbrellaren Ringnerven verlagert.

\section{Synapsenbildung}

In ihrer frühen Wachstumsphase zeigen die Neurite in der Regel keine Membrankontaktstrukturen zu benachbarten Neuriten oder Neuronen. Die Synapsenbildung beginnt mit einer lokalen Anhäufung von osmiophilem Material. In diesem Bereich erweitert sich der Interzellularspalt auf ca. $200 \mathrm{~nm}$; von den desmosomenartigen Strukturen der unreifen synaptischen Kontakte verbleibt lediglich wenig osmiophile amorphe Substanz, die den synaptischen Spalt ausfüllt. Danach lagern sich Neurosekretvesikel an. Sie entstehen im Perikaryon als Golgi-Vesikel und werden durch die Neurite bis zu den Synapsen transportiert. Alle ausdifferenzierten Synapsentypen besitzen Neuro-

Abb. 20 und 21. Tripedalia cystophora. Längsschnitte durch die Spitze der Rhopalaranlage. a Semidünner Schnitt mit Epidermis (ED) und abgegrenzten Lithocyten (LC), $1100 \mathrm{x}$. $b$ Junge Lithocyten (LC) mit einer großen Vakuole (Va) und zahlreichen kleinen Vakuolen (Va'), vesikulärem glatten endoplasmatischen Retikulum (ER) und zahlreichen Mitochondrien (M), 12 000x. Fix. 2 $c$ Ausdifferenzierte Lithocyten (LC) mit großer Vakuole (Va) und zahlreichen Interdigitationen (-), 5000x. Fix. 4. GD Gastrodermis, MG Mesogloea, N Nukleus. 21 Sinneszellen (SZ) des Sinnespolsters mit Rootlet (Ro) und Neuriten (Ne), 4500x. Fix. 1. EU Exumbrella, LC Lithocyte, N Nukleus, NZ Nervenzelle, Rh Rhopalium 

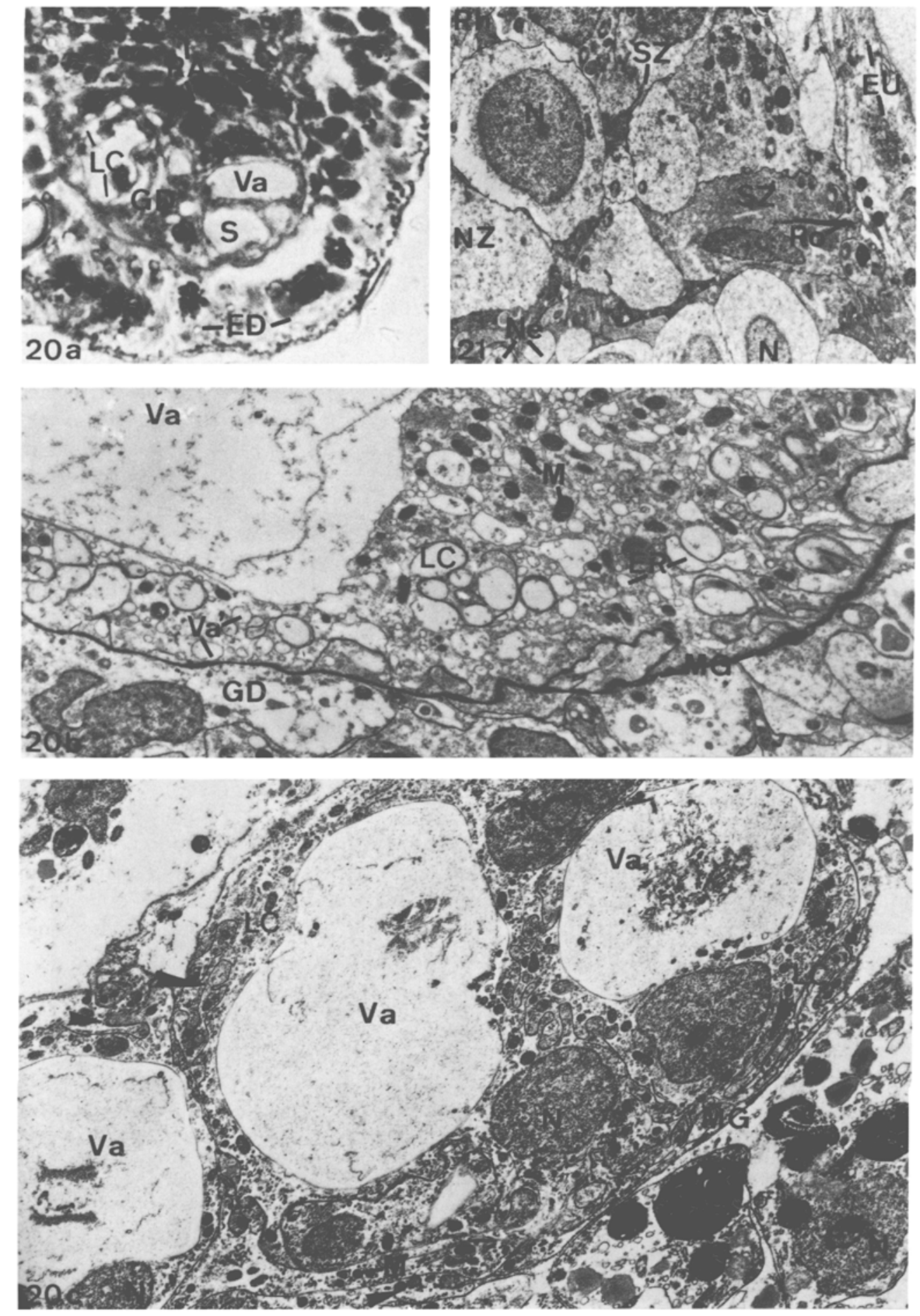
kret-Vesikel vom B-Typ, die einen Durchmesser von $180 \mathrm{~nm}$ aufweisen. Bei polaren Synapsen liegen diese Vesikel nur auf einer Seite des synaptischen Spaltes, bei symmetrischen Synapsen hingegen auf beiden Seiten. Symmetrische Synapsen treten sowohl axo-axonal als auch axo-somatisch auf.

\section{Die Differenzierung der Ganglienzellen}

Im Frühstadium der Linsenentwicklung des kleinen Linsenauges (klLA in Abb. 23a) liegt den Linsenzellen ein I-Zellkomplex (IZ in Abb. 23a) benachbart, dessen Zellen sich bald durch ihre Größe und die Entwicklung osmiophiler Schollen von den darüberliegenden Epithelzellen unterscheiden. Diese Ganglienzellen entwickeln sich aus I-Zellen (IZ in Abb. 23a). Jedoch ist ihre weitere Differenzierung nach der Vesikulationsphase von der der Sinneszellen und auch der Nervenzellen verschieden. In den jugendlichen Ganglienzellen ( $G Z$ in Abb. 23b) entsteht ein stark kondensiertes endoplasmatisches Retikulum (rER in Abb. 23b). Es besteht aus Zisternen, die dicht mit Ribosomen bedeckt sind und zusammen mit einigen Mitochondrien ( $\mathrm{M}$ in $\mathrm{Abb}, 23 \mathrm{~b}$ ) in Kernnähe liegen. In älteren Entwicklungsstadien nimmt die Dichte des Cytoplasmas stark ab, jedoch blejben die ER- oder Nissl-Schollen rund um den Kern ( $N$ in Abb. 23b) erhalten. Die Ganglienzellen bilden als multipolare Nervenzellen meist mehr als zwei Neurite aus. Diese verlaufen gemeinsam mit den Neuriten der Interneurone durch den Stielnerv. Im Rhopalium der Jungmeduse ist diese Entwicklung abgeschlossen, und man findet keine Entwicklungsstadien von Ganglienzellen mehr. Nach der Differenzierung dieser Schrittmacher der Schirmpulsation besitzt das Schlußstadium der Metamorphose alle Voraussetzungen der freien Beweglichkeit. An den ursprünglichen Polypen erinnert nach der Ablösung der frei schwimmenden Jungmeduse nur noch der Peridermsockel, den sie am Substrat zurückläßt.

\section{DISKUSSION}

Im Verlaufe der Metagenese der Cnidarier wird die Polypengeneration sexuell gebildet, während die vegetativen Entwicklungsprozesse sowohl die allotypische Zeugung sessiler Gonophoren oder freischwimmender Medusen als auch die Vermehrung identischer Individuen umfassen. Die Transformation eines Polypenteiles oder eines gesamten Polypen führt zur Frage der Zellgenealogie.

Abb. 22 und 23. Tripedalia cystophora. Längsschnitte durch den Glockenrand mit Rhopalarbasis. 22a Anlage des subumbrellaren Ringnerven (RN) mit Übergang zum exumbrellaren Stielnerven durch die radiale Óffnung der Mesogloea (MG), 4200x. Fix. 1. $b$ Interradialer Schnitt durch junge Nervenzellen (NZ) des Ringnerven, 4200 x. Fix. 2. MG Mesogloea, MGZ macrogranuläre Zelle, SU Subumbrella. 23a Längsschnitt durch die Rhopalarbasis in Stielnähe mit einem wenigzelligen Komplex aus I-Zellen (IZ) neben dem kleinen Linsenauge (kILA), 1000 x. $b$ Junge Ganglienzelle (GZ) mit rundem Kern (N) und ersten Nissl Schollen (rER), 15000x. Fix. 1. D Dictyosom. $c$ Ganglienzellen (GZ) gegen Ende der Metamorphose mit locker strukturiertem Cytoplasma und zahlreichen Nissl Schollen (rER), 15 000x. Fix. 1., M Mitochondrium 

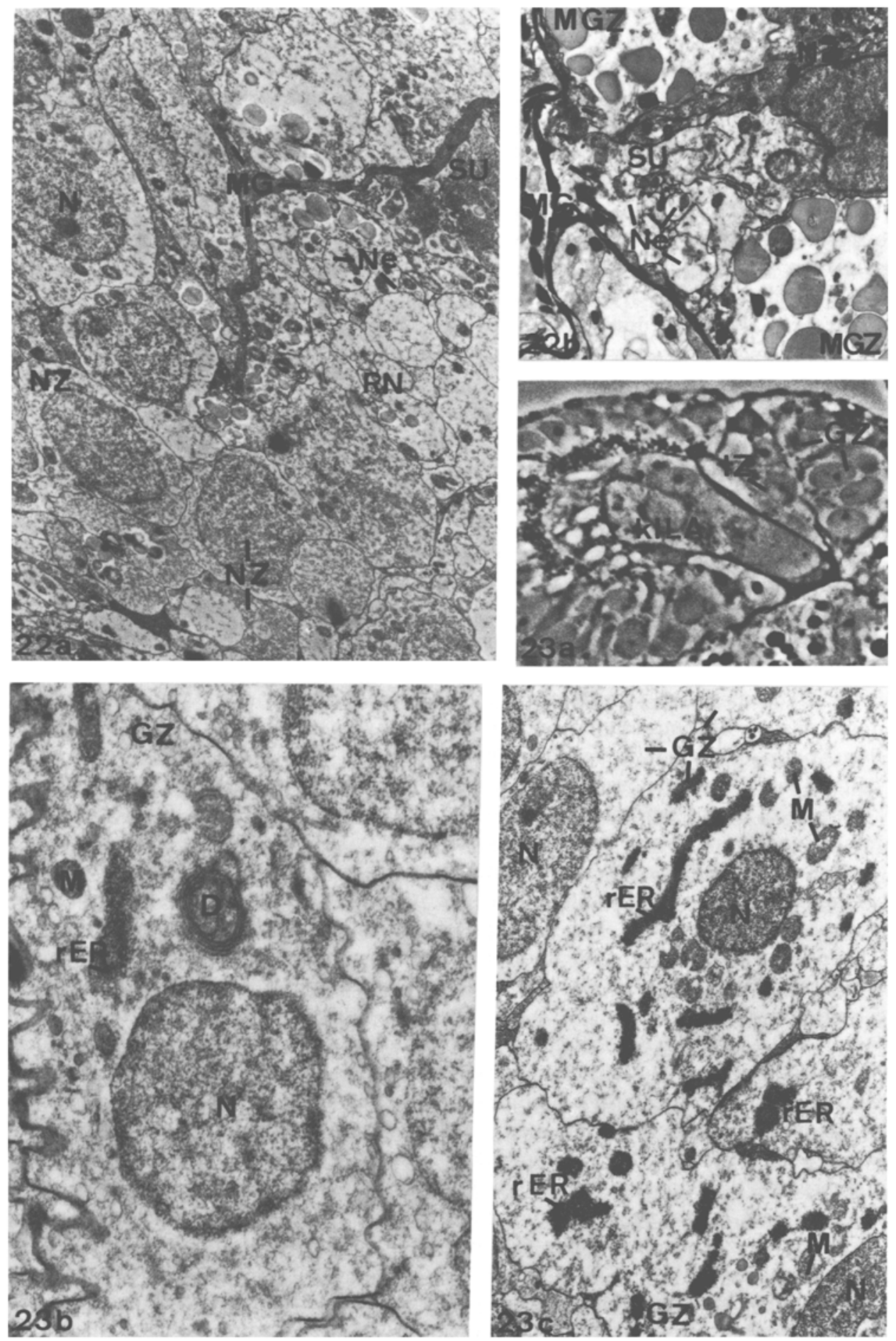


\section{Medusenbildung}

Die Medusenbildung kann von einer begrenzten Anzahl somatischer Zellen des Polypen oder eines Großteils seines Körpers ausgehen. Bei dieser Umordnung polypentypischer Zellen zu einer medusentypischen Gestalt handelt es sich nie um eine reine Morphallaxis, wie dies für die Regeneration bei Cnidariern charakteristisch ist (Tardent, 1960; Haynes \& Burnett, 1963). Bei den Hydrozoa entstehen die Medusen oder Gonophoren durch laterale Knospung am Polypen nach dem Prinzip der sogenannten Glockenkernmeduse. Auch wenn die Medusen sich nicht mehr ablösen, sondern als sessile oder medusoide Gonophoren zeitlebens am Polypen verbleiben (Kühn, 1914; Hertwig \& Hündgen, 1984), entsprechen sie dem Entwicklungsprinzip der Glockenkernmeduse (Frey, 1968; Tardent, 1978). Die bei Cladonema radiatum (Weiler-Stolt, 1960; Brien, 1966) und Podocoryne carnea (Frey, 1968; Boelsterli, 1978) besonders eingehend untersuchte Medusenknospung beginnt immer mit einer zweischichtigen Evagination, die zunächst nur Drüsen-, Nähr- und Epithelmuskelzellen aber keine I-Zellen enthält. Diese wandern auch nicht aus einem häufig postulierten I-Zellreservoir ein, sondern entstehen durch Dedifferenzierung vorhandener Epithelmuskelzellen (Brien, 1966) und bilden wie bei der Metamorphose von Tripedalia cystophora ein Blastem, den sogenannten Glockenkern. Dieses Blastem wird bei der Morphogenese vor allem für die Bildung der Subumbrella genutzt und gilt darüber hinaus als Organisator der Glockengestaltung (Frey, 1968; Naumov, 1969). Diese Aufgabe übernimmt bei den Cubopolypen hauptsächlich das peristomale Gewebe. Weitere Parallelen zwischen der Metamorphose der Cubozoen und der lateralen Medusenknospung der Hydrozoen ergeben sich zum einen aus der tetrameren Anlage des Gastrovaskularsystems und der Primärtentakel, die bei den Hydromedusen jedoch sekundären Veränderungen unterliegen können, zum anderen aus der Bildung einer quergestreiften Schwimm-Muskulatur und ihrer funktionellen Abhängigkeit von marginalen Ringnerven.

Bei einer Metamorphose wandelt sich ein Polyp vollständig in eine Meduse um; bei der Knospung bleibt der Polyp dagegen normalerweise unversehrt. Entweder entwikkeln sich an einem Polypen mehrere Medusenknospen gleichzeitig (z. B. Sarsia tubulosa: Kakinuma, 1966) oder es wird nur jeweils eine Medusenanlage gebildet (z. B. Cladonema radiatum: Weiler-Stolt, 1960 oder Craspedacusta sowerbii: Reisinger, 1957; Meurer \& Hündgen, 1978). Bei letzterer ist der Polyp sehr viel kleiner als die rasch wachsende Medusenanlage. Er überlebt den Knospungsvorgang nur dann, wenn auf den ersten nicht unmittelbar ein zweiter folgt; sonst wird das Polypenmaterial vollständig aufgebraucht (Reisinger, 1957), wie dies bei Coryne loveni und Eutima cirrhifera (Werner, 1983) oder bei der Primärmedusenbildung von Rathkea octopunctata (Werner, 1958; Bouillon \& Werner, 1965) immer der Fall ist. Diese Formen der Medusenknospung entsprechen prinzipiell der Metamorphose von Tripedalia cystophora. Eine noch gröBere Übereinstimmung tritt in Stöcken von Podocoryne carnea auf, bei der die Medusenbildung auch aus Autozoiden erfolgen kann (Brändle, 1971). Wie auch zu Beginn der Metamorphose der Cubozoa werden die Polypententakel eingeschmolzen, das Peristom umgeformt und Zellen zu einer Knospe dedifferenziert. Erst dann weicht die Entwicklung der Hydrozoen von der der Cubozoen $a b$, denn nur bei ersteren entsteht eine Glockenkernmeduse.

Derartige Totalumwandlungen von Polypen treten bei den Hydrozoen nur bei koloniebildenden Formen auf, wobei der Verlust eines Autozoids für die Kolonie 
unerheblich ist. Bei den solitären Cubopolypen begrenzt eine Totalumwandlung jedoch die Möglichkeit, sich durch Polypenknospung weiter zu verbreiten (Werner, 1983). Somit haben Cubopolypen nur eine begrenzte Lebensdauer. Ein weiterer Unterschied besteht in der Irreversibilität einer einmal begonnenen Metamorphose im Gegensatz zur Medusenknospung der Hydrozoen, die bis zur Bildung des als Organisator wirksamen Glockenkernes experimentell in eine Polypenknospung umgeleitet werden kann (Schmid, 1972, 1974).

Auch bei der terminalen Knospung der Scyphozoa, der Strobilation, sind Mechanismen aktiv, die der Metamorphose der Cubozoa vergleichbar sind. Bei der Strobilation kommt es zu zentripetalen Einschnürungen des Polypenkörpers von apikal nach basal. Sie können wie bei Aurelia aurita (Thiel, 1966; Spangenberg, 1965; Russell, 1970) oder Rhopilema verrilli (Calder, 1973) in Form einer polydisken Strobilation, oder wie bei Cassiopea andromeda (Gohar \& Eisawy, 1960; Ludwig, 1969) in Form einer monodisken Strobilation ablaufen. In beiden Fällen wird der Apex des Polypen nach dem Abbau bzw. Umbau des Tentakelringes durch metaplastische De- und Redifferenzierungsvorgänge in eine oder mehrere scheibenförmige Anlagen gegliedert, was zu einer oder mehreren Ephyralarven führt, die frei werden.

Nach meinen Beobachtungen ähnelt Cassiopea andromeda während ihrer Strobilation der metamorphosierenden Carybdea marsupialis sehr, da beide während der Einschmelzung der Tentakel eine deutliche Gliederung in Kopf- und Stielteil aufweisen. Im Gegensatz zu Cassiopea andromeda wird jedoch bei Carybdea marsupialis der Stiel im Laufe des Medusenwachstums allmählich kürzer und bleibt nur vorübergehend am Apikalteil der frei schwimmenden Meduse sichtbar, bis er durch weiteres Wachstum in die Glocke integriert wird. Cassiopea andromeda läßt hingegen den Stielrest zurück, der zu einem neuen Polypen regeneriert.

Bei der Strobilation wie auch bei der Metamorphose werden die Polypententakel zu Rhopalien umgebildet, von denen bei Cubozoen immer vier, bei Scyphozoen hingegen 8 oder mehr angelegt werden. Die Medusententakel sind Neubildungen; das Hypostom und das Peristom werden zum Manubrium und zur Subumbrella der jungen Meduse bzw. der Ephyralarve. Die Morphogenese des Gastrovaskularsystems differiert jedoch, denn die Cubomedusen legen peripher 4 Gastraltaschen, die Scyphomedusen hingegen ein röhrenförmiges und verzweigtes Gastrovaskularsystem an (Kramp, 1943; Russell, 1970).

Die bisherigen Ausführungen machen die Vorstellung wahrscheinlich, daß der Bildung der Medusen in allen Klassen ein gemeinsames Entwicklungsprinzip zugrunde liegt. Abb. 1 stellt die Lebenszyklen der Hydrozoa (mit lateraler Knospung), der Scyphozoa (mit Strobilation) und der Cubozoa (mit Metamorphose) einander gegenüber.

In allen drei Klassen beginnt die Ontogenese der Tiere mit der Anhaftung einer pelagischen Planula-Larve (Bodo \& Bouillon, 1968; Okada, 1927; Thiel, 1936) und ihrer Metamorphose zum sessilen Polyp. Die sessile Phase ist zur blastogenetischen Bildung der Meduse befähigt. Diesem Ubergang zur sexuellen Generation liegt die evolutionistische Idee zugrunde (Haeckel, 1874), daß die Meduse einen umgewandelten, mobilen Polypen darstellt.

Alle beschriebenen morphogenetischen Mechanismen der Medusenbildung sowohl das Prinzip des Glockenkerns als auch jenes der De- und Regenerationsvorgänge im Tentakelbereich - deuten darauf hin, daß es sich in keinem Fall um morphal- 
Tab. 1. Lebenszyklen der Cnidaria

\begin{tabular}{|c|c|c|}
\hline Hydrozoa & Scyphozoa & Cubozoa \\
\hline Planula & Planula & Planula \\
\hline Metamorphose & Metamorphose & Metamorphose \\
\hline+ & $\downarrow$ & 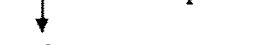 \\
\hline Polyp & Polyp & Polyp \\
\hline & & \\
\hline asexuelle & asexuelle & \\
\hline Fortpflanzung & Fortpflanzung & Metamorphose \\
\hline Meduse & Meduse & Meduse \\
\hline sexuelle & sexuelle & sexuelle \\
\hline Fortpflanzung & Fortpflanzung & Fortpflanzung \\
\hline Planula & Planula & Planula \\
\hline
\end{tabular}

laktische Prozesse vergleichbar der Polypenregeneration handelt. Die wesentlich komplexer organisierte Meduse kann nur aus Differenzierungsvorgängen hervorgehen, die ausschließlich einem Blastem möglich sind. Zweifellos ist diese Blastembildung in allen drei Medusen bildenden Klassen nachweisbar; daher besteht zwischen den Knospungsvorgängen und der Metamorphose kein grundsätzlicher, sondern lediglich ein gradueller Unterschied, der für die Klassen charakteristisch zu sein scheint.

\section{Zellgenealogie}

Das Ausgangsmaterial für die Metamorphose der Cubozoa (Werner, 1975, 1976) ist der Cubopolyp. Er besteht wie alle Cnidarier aus einer einschichtigen Epidermis und Gastrodermis (Tab. 2, linke Hälfte). Letztere wird von nur zwei Zelltypen gebildet, von Nährzellen und von Drüsenzellen, die ohne nennenswerte cytologische Veränderungen im Verlaufe der Metamorphose das neue Gastrovaskularsystem der Meduse bilden. Sowohl Drüsen- als auch Nährzellen sind in dieser Phase mitotisch aktiv.

Die Epidermis der Cubopolypen besteht aus Nesselzellen, Nervenzellen, Sinneszellen und Epithelmuskelzellen mit glatten Myofibrillen (Werner et al., 1976; Chapman, 1978). I-Zellen, die als Vorläufer der Nesselzellen postuliert werden müssen, konnten bis heute nicht nachgewiesen werden und bleiben deshalb in der schematischen Ubersicht unberücksichtigt. Die Nessel-, Nerven- und Sinneszellen unterliegen alle im Verlaufe der Metamorphose einer Autolyse und gehen als Zellen quantitativ verloren. Sie treten aus dem Gewebeverband heraus oder werden in Bruchstücken von den Nährzellen der Gastrodermis phagozytiert. Dieser Vorgang erinnert an die Regressionsvorgänge im Tierreich, wie es beispielsweise auch die Metamorphose der AscidienLarve oder der Kaulquappen darstellt (de Duve \& Wattiaux, 1965; Cloney, 1966).

Die Epithelmuskelzellen hingegen treten in eine Dedifferenzierungsphase ein. Sie erfaßt zunächst die Myofibrillen, dann die basalen Zellausläufer, die zentrale Vakuole und schließlich einen Teil der Mitochondrien. Endet die Dedifferenzierung hiermit, so 


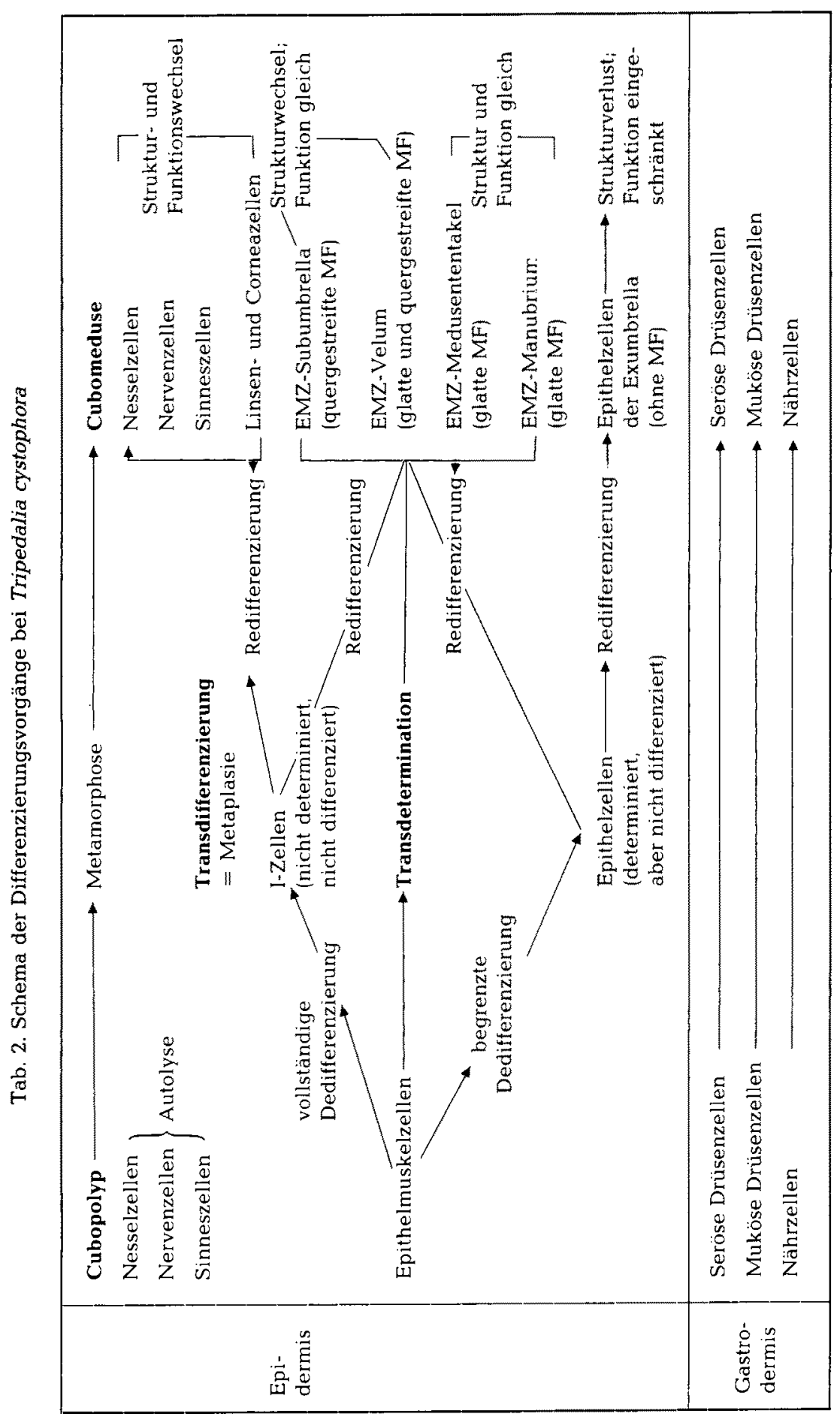


liegt eine "begrenzte Dedifferenzierung" vor (Tab. 2, Mitte). Sie führt zu Zellen, die zwar weiterhin zu Epithelzellen determiniert sind, aber ihre spezielle Differenzierung verloren haben, so daß alle Epithel-Zelltypen der Meduse aus ihnen hervorgehen können (Tab. 2, rechte Hälfte). Es liegt eine Transdetermination vor, die der bei den Imaginalscheiben der Insekten vergleichbar ist (Spemann \& Mangold, 1924; Hadorn, 1965, 1968; Benzer \& Hotta, 1972). Schreitet die Dedifferenzierung weiter fort, so geht auch die Determination zu Epithelzellen verloren. Es handelt sich um eine vollständige Dedifferenzierung, die zu embryonalen Zellen, den I-Zellen führt. Aus ihnen entstehen nicht nur Epithelzellen, sondern auch alle anderen epidermalen Zelltypen (Lentz, 1965) wie Nesselzellen, Nervenzellen, Sinneszellen, Linsenzellen und Corneazellen. Es liegt somit eine typische Transdifferenzierung oder Metaplasie vor, wie sie unter anderem von den Iriszellen des Molchauges bekannt ist (Byers \& Porter, 1964; Starck, 1965; Yamada et al., 1973). Beim Polypen ist nur die Determination zu Epithelzellen reversibel, die zu den anderen Zelltypen nicht (Frey, 1968; Schmid, 1972). Das unterschiedliche Schicksal der verschiedenen Zelltypen steht offensichtlich in enger Beziehung zur Zellproliferation, denn alle nicht mehr teilungsfähigen Zelltypen unterliegen der Autolyse, während die Epithelmuskelzellen und die Gastrodermiszellen überleben. Daß die teilungsfähigen Epithelmuskelzellen zusätzlich in eine Phase der Dedifferenzierung eintreten, ermöglicht die Bildung jenes Blastems, das die Neugestaltung auf dem Niveau der Zellverbände und Einzelzellen zuläßt. Es ist die Voraussetzung sowohl für die Ergänzung verlorengegangener Zelltypen (Epithelzellen, Epithelmuskelzellen und Nesselzellen) als auch für die Ausbildung von Sinneszellen und -Organen eines komplexer entwickelten Nervensystems und der Schwimm-Muskulatur (Laska \& Hündgen, 1984).

Danksagungen. Diese Arbeit ist dem Andenken an unseren verstorbenen Kollegen Dr. B. Werner gewidmet. Seine Forschungsarbeit über Tripedalia cystophora ist Grundlage sowohl meiner Diplomarbeit als auch der Dissertation gewesen. Wir werden uns seiner Hilfsbereitschaft und der zahlreichen Anregungen immer dankbar erinnern. Herrn Professor Dr. M. Hündgen danke ich für die zahlreichen Hinweise und Ratschläge bei der Erstellung der Arbeit. Für technische Assistenz danke ich Frau B. Zarbock. - Die Arbeit wurde aus Mitteln der DFG gefördert (Hu/328/1-1)

\section{LITERATUR}

Arneson, A. C. \& Cutress, C. E., 1976. Life history of Carybdea alata Reynaud, 1830 (Cubomedusae). In: Coelenterate ecology and behavior. Ed. by G. O. Mackie. Plenum Press, New York, $227-236$.

Benzer, S. \& Hotta, Y., 1972. Mapping of behavior in Drosophila mosaics. - Nature, Lond. $240,527$.

Bodo, F. \& Bouillon, J., 1968. Étude histologique du développement embryonnaire de quelques hydroméduses de Roscoff: Phialidium hemisphaericum, Obelia spec., Sarsia eximina, Podocoryne carnea, Gonionemus vertens. - Cah. Biol. mar. 9, 69-104.

Boelsterli, U., 1978. An electron microscopic study of early developmental stages in the anthomedusa Podocoryne carnea. - J. Morphol. 154, 259-290.

Bouillon, J. \& Werner, B., 1965. Production of medusae buds by the polyp of Rathkea octopunctata. Helgoländer wiss. Meeresunters. 12, 137-148.

Brändle, E., 1971. Bedeutung der kolonialen Komponente für die Bildung und Differenzierung der Medusen von Podocoryne carnea. - Wilhelm Roux Arch. EntwMech. Org. 166, 254-286.

Brien, P., 1966. Biologie de la reproduction animale. Masson, Paris, $292 \mathrm{pp}$.

Byers, B. \& Porter, K. R., 1964. Oriented microtubules in elongating cells of the developing lens rudiment after induction. - Proc. ntn. Acad. Sci. U.S.A. 52, $1091-1099$. 
Calder, D. R., 1973. Laboratory observations on the life history of Rhopileum verrilli (Scyphozoa) Rhizostomeae. - Mar. Biol. 21, 109-114.

Chapman, D. M., 1978. Microanatomy of the cubopolyp Tripedalia cystophora Conant. - Helgoländer wiss. Meeresunters. 31, 128-168.

Cloney, R. A., 1966. Cytoplasmic filaments and cell movements: Epidermal cells during ascidian metamorphosis. - J. Ultrastruct. Res. 14, 300-328.

Conant, F. S., 1898. Cubomedusae. - Mem. Biol. Lab. Johns Hopkins Univ, 4, 1-61.

Duve, C. de \& Wattiaux, R., 1965. Functions of lysosomes. - A. Rev. Physiol. 28, 435-492.

Frey, J., 1968. Die Entwicklungsleistungen der Medusenknospen und Medusen von Podocoryne M. Sars nach Isolation und Dissoziation. - Wilhelm Roux Arch. EntwMech. Org. 60, 428-464.

Gohar, H. A. F. \& Eisawy, A. M., 1960. The development of Cassiopea andromeda (Scyphozoa Medusae). - Publs mar. biol. Stn Ghardaqa 11, 147-190.

Hadorn. E., 1965. Problems of determination and transdetermination. - Brookhaven Symp. Biol. 18, 148.

Hadorn, E., 1968. Transdetermination in cells. - Scient. Am. $219(5), 110$.

Haeckel, E., 1874. Die Gastraeatheorie, die phylogenetische Klassifikation des Tierreiches und die Homologie der Keimblätter. - Jena. Z. Naturw. 8, 1-55.

Haynes, J. F. \& Burnett, A. L., 1963. Dedifferentiations and redifferentiation of cells in Hydra viridis. - Science, N. Y. 142, 1481-1485.

Hennig, W., 1979. Taschenbuch der speziellen Zoologie. Wirbellose I. Fischer, Jena, 290-294.

Hertwig, I. \& Hündgen, M., 1984. Gonophorenbildung und Keimzellentwicklung bei Hydractinia echinata. - Zool. Jb. (Anat. Ontogenie Tiere) 112, 113-136.

Kakinuma, Y., 1966. Life cycle of a hydrozoan Sarsia tubulosa (Sars). - Bull. mar. biol. Stn Asamushi $12,207-210$.

Kramp, P. L., 1943. On the development through alternating generations especially in coelenterates. - Vidensk. Meddr dansk. naturh. Foren. 107, 13-32.

Kühn, A., 1910. Die Entwicklung der Geschlechtsindividuen der Hydromedusen. - Zool. Jb. (Anat. Ontogenie Tiere) $30,43-174$.

Kühn, A., 1914. Entwicklungsgeschichte und Verwandtschaftsbeziehungen der Hydrozoen. Ergebn. Forschr. Zool. 4, 1-284.

Laska, G. \& Hündgen, M., 1982. Morphologie und Ultrastruktur der Lichtsinnesorgane von Tripedalia cystophora Conant (Cnidaria, Cubozoa). - Zool. Jb. (Anat. Ontogenie Tiere) 108, 107-123.

Laska, G. \& Hündgen, M., 1984. Die Ultrastruktur des neuromuskulären Systems der Medusen von Tripedalia cystophora und Carybdea marsupialis (Cubozoa). - Zoomorphology 104, 163-170.

Lentz, T. L., 1965. The fine structure of differentiation of interstitial cells in Hydra. $-Z$. Zellforsch. mikrosk. anat. 67, 547-560.

Ludwig, F. D., 1969. Die Zooxanthellen bei Cassiopea andromeda und ihre Bedeutung für die Strobilation. - Zool. Jb. (Anat. Ontogenie Tiere) 86, 238-277.

Meurer, M. \& Hündgen, M., 1978. Licht- und elektronenmikroskopischer Bau der Süßwassermeduse Craspedacusta sowerbii. - Zool. Jb. (Anat. Ontogenie Tiere) 100,485-508.

Naumov, D. V., 1969. Hydroids and Hydromedusae of the USSR. Israel Program for Scientific Translations, Jerusalem, $672 \mathrm{pp}$.

Okada, Y. K., 1927. Note sur l'ontogenie de Charybdea rastonii Haacke. - Bull. biol. Fr. Belg, 61, 241-249.

Pearse, J. S. \& Pearse, V. B., 1978. Vision in cubomedusan jellyfishes. - Science, N. Y. 199, 458.

Reisinger, E., 1957. Zur Entwicklungsgeschichte und Entwicklungsmechanik von Craspedacusta (Hydrozoa, Limnotrachylina). - Z. Morph. Okol. Tiere 45, 656-698.

Russell, F. S., 1970. The medusae of the British Isles. Univ. Press, Cambridge, 2, 1-283.

Schmid, V., 1972. Untersuchungen über die Dedifferenzierungsvorgänge bei Medusenknospen und Medusen von Podocoryne carnea M. Sars, - Wilhelm Roux Arch. EntwMech. Org. 169, 281-307.

Schmid, V., 1974. Regeneration in medusa buds and medusae of Hydrozoa. - Am. Zool. 14, 773-781.

Spangenberg, D. B., 1965. A study of strobilation in Aurelia aurita under controlled conditions. - J. exp. Zool. 160, 1-10.

Spemann, H. \& Mangold, H., 1924. Uber die Induktion von Embryonalanlagen durch Implantation artfremder Organisatoren. - Wilhelm Roux Arch. EntwMech. Org. 100, 599-638.

Starck, D, 1965. Embryologie. Thieme, Stuttgart, 693 pp. 
Tardent, P., 1960. Principles governing the process of regeneration in hydroids. In: 18th Growth Symposium. The Ronald Press, New York, 21-43.

Tardent, P., 1978. Coelenterata, Cnidaria. In: Morphogenese der Tiere. Hrsg. von F. Seidel. Fischer, Stuttgart, $1(1), 1-415$.

Thiel, Hj., 1966. The evolution of Scyphozoa. In: The Cnidaria and their evolution. Ed. by W. J. Rees. Acad. Press, London, 77-117.

Thiel, M. E., 1936. Scyphomedusae: Cubomedusae. - Bronns Kl. Ordn. Tierreichs 2 (2), 173-307.

Weiler-Stolt, B., 1960. Über die Bedeutung der interstitiellen Zellen für die Evolution und Fortpflanzung mariner Hydroiden. - Wilhelm Roux Arch. EntwMech. Org. 152, 398-454.

Werner, B., 1958. Die Verbreitung und das jahreszeitliche Auftreten der Anthomeduse Rathkea octopunctata (M. Sars) sowie die Temperaturabhängigkeit ihrer Entwicklung und Fortpflanzung. - Helgoländer wiss. Meeresunters. 6, 137-170.

Werner, B., 1973. Spermatozeugmen und Paarungsverhalten bei Tripedalia cystophora (Cubomedusae). - Mar. Biol. 18, 212-217.

Werner, B., 1975. Bau und Lebensgeschichte des Polypen von Tripedalia cystophora (Cubozoa, class. nov. Carybdeidae) und seine Bedeutung für die Evolution der Cnidaria. - Helgoländer wiss. Meeresunters. 27, 461-504.

Werner, B., 1976. Die neue Cnidarierklasse Cubozoa. - Verh. dt. zool. Ges, 69, 230.

Werner, B., 1983. Die Metamorphose des Polypen von Tripedalia cystophora (Cubozoa, Carybdeidae) in die Meduse. - Helgoländer Meeresunters. 36, 257-276.

Werner, B., Cutress, C. E. \& Studebaker, J. P., 1971. Life cycle of Tripedalia cystophora Conant (Cubomedusae). - Nature, Lond. 232, 582-583.

Werner, B., Chapman, D. M. \& Cutress, C. E., 1976. Muscular and nervous system of the cubopolyp (Cnidaria). - Experientia, 32, 1047-1048.

Yamada, T., Rees, D. H. \& McDevitt, D. S., 1973. Transformation of iris into lens in vitro and its dependency on neural retina. - Diff. Res. Biol. Div. 1, 65-82.

Yamaguchi, M. \& Hartwick, R., 1980. Early life history of Chironex fleckeri (Class Cubozoa). In: Developmental and cellular biology of coelenterates. Ed. by P. Tardent. Elsevier/North Holland Biomedical Press, Amsterdam, 11-16.

Yamasu, T. \& Yoshida, M., 1976. Fine structure of complex ocelli of a cubomedusan Tamoya bursaria Haeckel. - Cell Tissue Res. 170, 325-340. 